\title{
Investigating The Effect of Surface Finishing On Performance of Designed Aerostatic Bearing For Its Improved Precision Applications
}

\author{
Karan Singh Jamwal \\ Thapar Institute of Engineering and Technology \\ Anant Kumar Singh ( $\sim$ anantsingh@thapar.edu ) \\ Thapar University https://orcid.org/0000-0002-0080-3730
}

\section{Kunal Arora}

Thapar Institute of Engineering and Technology

\section{Sunil Kumar Paswan}

Thapar Institute of Engineering and Technology

\section{Research Article}

Keywords: Aerostatic bearing, pressure distribution, surface roughness, magnetorheological (MR) polishing fluids, MR finishing, load carrying capacity

Posted Date: August 13th, 2021

DOl: https://doi.org/10.21203/rs.3.rs-692081/v1

License: (9) This work is licensed under a Creative Commons Attribution 4.0 International License. Read Full License 


\title{
Investigating the Effect of Surface Finishing on Performance of Designed Aerostatic Bearing for its Improved Precision Applications
}

\author{
Karan Singh Jamwal ${ }^{1}$, Anant Kumar Singh ${ }^{2 *}$, Kunal Arora ${ }^{1}$, Sunil Kumar Paswan ${ }^{1}$ \\ ${ }^{1}$ Research Scholar, Department of Mechanical Engineering, Thapar Institute of Engineering and Technology, \\ Patiala 147004, India \\ ${ }^{2 *}$ Corresponding Author: Associate Professor, Department of Mechanical Engineering, Thapar Institute of \\ Engineering and Technology, Patiala 147004, India, \\ Email: anantsingh@thapar.edu, Tel.: +91-175-239-3086; Fax: +91-175-2364498
}

\begin{abstract}
:
Aerostatic bearing is an ultra-precision component that uses a spindle surrounded by a thin film of air. Due to the high accuracy of aerostatic bearing, the demand for these components is very high in electronic, instrumentation, healthcare, and other manufacturing or processing industries. In the present work, the main focused area is on the experimental determination of the effect of roughness parameter on the performance of the aerostatic journal and thrust bearings. To achieve the aim, the aerostatic bearing is designed based on theoretical analysis. The present design is numerically investigated by simulation of airflow in ANSYS Fluent with computational fluid dynamics module. The results from the simulation are validated by the results generated for pressure distribution in previous researches. After performing the finishing on the bearing and spindle surface, the manufactured components are assembled for analysing the variation in radial and axial loads acting on the spindle with the spindle displacement $(1-5 \mu \mathrm{m})$ in the direction of the load at supply pressures (36 bar) in the clearance of $30 \mu \mathrm{m}$. For surface improvement of the air bearing, three different techniques are used namely machining, grinding, and magnetorheological finishing. For each roughness reduction technique, the variation in axial and radial loads acting on the spindle is determined with variation in spindle displacement. The experimental results showed the increase in load capacity due to improvement in the surface finish for journal bearing and thrust bearing at $5 \mu \mathrm{m}$ displacement in the spindle is found to be $0.68 \mathrm{~N}$ for machining to grinding and $2.0 \mathrm{~N}$ from grinding to magnetorheological finishing respectively. The results determined for the surface finish parameter reveals the effect of surface roughness on the load-carrying capacity of the aerostatic journal and thrust bearing. The current study on the surface finishing of aerostatic bearing is found effective for the applications such as drives
\end{abstract}


in production machines where good grade of surface finish are the major parameters for improving the overall functional efficiency.

Keywords: Aerostatic bearing; pressure distribution; surface roughness; magnetorheological (MR) polishing fluids; MR finishing; load carrying capacity.

\section{Introduction}

Air bearing technology is boosted in the last two to three decades as the industrial application for micro-machining and high precision equipment has increased. The flow and distribution of air in aerostatic bearing affect the static and dynamic characteristics which are dependent on the feeding system. The microchannel structure of the restrictor provides the uniformly distributed flow over the entire surface which thereby increases stiffness and load-carrying capacity [1]. The performances are also influenced by the clearance, surface roughness, mass flow rate, supply pressure, air film thickness, length to diameter ratio, and design of the restrictors [2,3]. The other factor that takes into design consideration is the material selection for air bearing. The spindle material should be lightweight, high hardness and wear as well as corrosion resistance. For the outer casing of the bearing, the material should have stability, corrosion resistance, and a high modulus of elasticity to avoid vibration and distortion [4].

The major priority of aerostatic bearing design is to predict its flow characteristics which show the feasibility of design based on pressure ratio and pressure distribution within clearance. Kassab et al. [4] experimentally examined that with the increase in orifice diameter to bearing outer length ratio (dimensionless supply hole diameter), the pressure distribution is affected. The ratio increases both load-carrying capacity and mass flow rate as there is a reduction in film thickness and supply pressure. Further, the authors [5,6] discussed the finite element method to analyze the airflow behavior and pressure distribution within the bearing surface and spindle. This results from the numerical solution show the influence of geometrical characteristics on the performance efficacy of the aerostatic bearing. Chen et al. [7] investigated the static and dynamic characteristics of a rigid spindle supported by aerostatic bearings which are compensated by orifices and inherences. The experimental data shows that the use of pocketed type orifice rather than inherent orifice leads to the enhancement in load carrying capacity, inertial forces, and stiffness by minimizing instability induced in the aerostatic bearing system. The design of the restrictor is dependent on the geometrical parameters of the orifice such as recess shape, supply hole diameter, and orifice length. The recess shapes or pressure equalizing grooves used in gas-lubricated bearing are spherical and rectangular which shows its effect on load capacity, mass flow rate, and stability of bearing. 
The spindle and flow control system of the aerostatic bearing is the most important components and the efficacy of the bearing is dependent on their designing specifications. The designing of the spindle and bearing are influenced by the surface properties such as roughness and manufacturing defects like circumferential and axial errors which include waviness, convexity, and concavity [8]. The error in surface finish can affect air pressure distribution, load capacity, and stiffness by non-uniformity in fluid flow especially in the high-pressure region [9]. The performance of aerostatic bearing is enhanced by minimizing these defects and improving surface properties. Early, the literature on the effects of manufacturing errors and roughness characteristics on aerostatic bearing has been discussed [10, 11] However, the wave models presented in these studies show large variations in analytical and practical studies. Pande and Somasundaram [12] analyzed the theoretical analysis of the effect of manufacturing errors and roughness patterns on the performance of aerostatic journal bearings. The results show that the reduction in load-carrying capacity and airflow rate is due to the deviation from actual surface geometry. Kwan and Post [13] relate the manufacturing errors with bearing parameters such as orifice diameter and surface characteristics. The theoretical analysis proves that the load capacity and stiffness of aerostatic bearing are sensitive to different types of manufacturing errors and this sensitivity is defined by the tolerance ranges. Nagaraju et al. $[14,15]$ demonstrated the theoretical effect of surface characteristics such as surface roughness, surface pattern and shell deformation on bearing performance of an orifice compensated bearing. The results indicate that the influence of the surface roughness helps in evaluating the accurate prediction of numerical values for bearing performance data. Sharma and Kushare [16] examine the performance of journal bearing systems with different inlet flow compensation based on the surface pattern. Again, the evaluated data show that roughness orientation affects the bearing performance and the proper selection roughness pattern helps in enhancing the bearing performance. Zhang et al. [17] highlighted that the ultra-precision diamond turning (UPDT) technique is best for manufacturing aerostatic bearing spindle with small tolerance. However, due to uncontrollable finishing forces, the fine finishing is not achievable by this process. Further, to analyze surface roughness theoretically, Dal and Karacay [18] proposed Reynold's equation model which is used with a clearance function that has a direct relation with bearing and spindle surfaces. This model showed that for the smooth surface, the load capacity is higher when the eccentricity ratio varies from 0 to 0.5 but the load capacity is higher and system vibrations are lower when eccentricity ratio is larger than 0.5 . Also, for the weighty spindle, the eccentricity is higher. So, the spindle oscillates around the bearing center for the higher value of surface roughness.

Further, on the basis of literature survey, it can be seen that surface finish of aerostatic bearing play an important role in enhancing its functional efficacy. The fine finished surface of the bearing tends to enhance the load-carrying capacity and airflow rate while functioning. Further, mostly the surface 
finish of aerostatic bearing is done theoretically and very little work is experimentally validated. Therefore, to overcome the aforementioned demerits, an attempt has been made in the present study, to experimentally evaluate the load-bearing capacity of orifice-fed aerostatic bearing on the basis of surface characteristics of journal and spindle. Initially, the flow of air through the orifice is simulated numerically using Fluent which shows the velocity and pressure profiles at different pressure ranges to provide the optimum design of the orifice. This ensures uniform pressure distribution within the clearance region. Next, the maximum load-bearing capacity for thrust and journal bearing is evaluated using different surface characteristics. The processes used to achieve the desired surface roughness values are surface grinding and magnetorheological finishing. In the present work, the magnetorheological finishing process is used to achieve the desired roughness values for the spindle and journal. Finally, at each roughness value, the maximum load capacity at a pressure range (0.3-0.6 $\mathrm{MPa}$ ) is evaluated. The range of pressure is selected based on the orifice design of the present aerostatic bearing. The eccentricity values are varied from $1 \mu \mathrm{m}$ to $5 \mu \mathrm{m}$ as the load-carrying capacity decreases at a higher value of eccentricity ratio [18]. The experimental results are compared with the literature on the performance of the aerostatic bearing and the benefits of this study are discussed.

\section{Analysis of the designed aerostatic bearing using computational fluid dynamics (CFD) simulation}

In this work, initially, the feasibility of the designed journal and thrust bearing are studied by analysing the pressure distribution studied through CFD simulation and validated with the existing literature of the same components. Primarily, the computer-aided design (CAD) model of journal and thrust bearing is generated using the software "PTC Creo Parametric 3.0 F00" as depicted in Fig. 1. Using the CAD model (Fig. 1a), the CFD simulation is performed through the fluent module of the ANSYS workbench (Version 2013) to acknowledge its functionality. Figs. 1 (b) and (c) represent the wire-frame image of the sectional view of the journal bearing and thrust bearing (thrust plate and shaft). Further, the working of simulation of the journal and thrust bearing are depicted in Figs. 2 (a) and (b) respectively. In both types of the aforesaid bearings the pressurized air enters into the clearance gap through the pressure inlet valve and exits to the atmosphere through the edge of the bearing as shown in Figs. 2 (a) and (b). The CFD analysis is carried out to validate the present design of the modified aerostatic bearing. The fluid flow equations such as the continuity equation, energy equation, and momentum equation are solved using Ansys Fluent. For this study, the fluid is considered as compressible which flows under the isothermal condition and obeys the ideal gas law [5]. The upstream or flow of inlet air is assumed as an inlet pressure, so the flow velocity is determined based on total pressure and gauge pressure values, and the downstream or outlet is assumed to be at atmospheric pressure. The dimensions along 
with operating conditions for thrust bearing and journal bearing used in simulation and experiment are given in Table 1 and Table 2.

From geometry as shown in Fig. 2, the two nozzles from each column are used as an air inlet and the two sides of the bearing edge i.e., clearance gap is used as an outlet. As the bearing clearance in both thrust and journal bearing is very small, so to avoid failed meshes, the minimum number of nodes and elements generated in meshing are 231353 and 515901 respectively.

For turbulent flow model, the viscosity $\left(\mu_{T}\right)$ is evaluated by using the standard k-epsilon model [19] as given in Eq. (1).

$$
\mu_{T}=\rho C_{\mu} \frac{k^{2}}{\varepsilon}
$$

Where, $\rho$ is the density of the fluid, $\mathrm{k}$ is turbulence kinetic energy, $\epsilon$ is dissipation rate of turbulence kinetic energy, and $C_{\mu}$ signifies the model constant

The turbulence kinetic energy and its dissipation rate are expressed in the form of the transport equations which is derived from momentum equation and physical reasoning. These equations can be expressed as in Eqs. (2) and (3) respectively.

$\frac{\partial k}{\partial t}+\frac{\partial\left(k u_{i}\right)}{\partial x_{i}}=\frac{\partial}{\partial x_{i}}\left(\frac{v_{t}}{\sigma_{k}} \frac{\partial k}{\partial x_{i}}\right)+\frac{\partial u_{i}}{\partial x_{j}}\left(\frac{\partial u_{j}}{\partial x_{i}}+\frac{\partial u_{i}}{\partial x_{j}}\right) v_{t}-\varepsilon$

$\frac{\partial \varepsilon}{\partial t}+\frac{\partial\left(\varepsilon u_{i}\right)}{\partial x_{i}}=\frac{\partial}{\partial x_{i}}\left(\frac{v_{t}}{\sigma_{\varepsilon}} \frac{\partial \varepsilon}{\partial x_{i}}\right)+\frac{\partial u_{i}}{\partial x_{j}}\left(\frac{\partial u_{j}}{\partial x_{i}}+\frac{\partial u_{i}}{\partial x_{j}}\right) v_{t} \frac{\varepsilon}{k} C_{1 \varepsilon}-\frac{\varepsilon^{2}}{k} C_{2 \varepsilon}$

where, $u_{i}$ and $u_{j}$ are velocity components, and $C_{\mu}, C_{1 \epsilon}, C_{2 \epsilon}, \sigma_{k}$ and $\sigma_{\epsilon}$ are model constant with values $0.09,1.44,1.92,1.0$ and 1.3 respectively [20]. These values are derived from experiments and analytical optimization with assumption of fluid as air. The model for pressure distribution is expressed by the general form of modified Reynold's equation as Eq. (4)

$\frac{\partial}{\partial y}\left(\rho h^{3} \frac{\partial p}{\partial y}\right)+\frac{\partial}{\partial z}\left(\rho h^{3} \frac{\partial p}{\partial z}\right)=6 \mu U \frac{\partial(\rho h)}{\partial y}+12 \mu \frac{\partial(\rho h)}{\partial t}+12 \rho V_{i n j}$

where, $V_{\text {inj }}$ is simplified using Naiver-Stokes equation which is expressed in cylindrical coordinates as Eq. (5) [21].

$V_{\text {inj }}(y, z, t)=-\frac{1}{4 \mu} \frac{\partial p}{\partial x}\left[\frac{d_{o}^{2}}{4}-\left(y-y_{i}\right)^{2}-\left(z-z_{i}\right)^{2}\right]$

The Eq. (5) is used for thrust bearing system, whereas, in the case of a journal bearing, the velocity of air is evaluated in circumferential and radial direction. For this purpose, the modified Reynold's equation can be transformed in term of radial polar coordinates as given in Eq. (6).

$\frac{\partial}{\partial r}\left(p r h^{3} \frac{\partial p}{\partial y}\right)+\frac{1}{r} \frac{\partial}{\partial \theta}\left(p h^{3} \frac{\partial p}{\partial \theta}\right)=12 \mu\left[v_{r} \frac{\partial(p r h)}{\partial r}+v_{\theta} \frac{\partial(\rho h)}{\partial \theta}\right]+\frac{\partial(p h)}{\partial t}$

where, $\mathrm{r}$ and $\theta$ are the radial and circumferential components, and $v_{r}$ and $v_{\theta}$ are the velocity in radial and circumferential direction, $\mathrm{P}$ is the fluid film pressure, and h signifies the fluid film thickness. 
The boundary condition for the inlet is set as pressure-inlet with appropriate values of total and inlet gauge pressure. The specification method for turbulence is specified as k-epsilon with turbulent kinetic energy and dissipation rate constants as 0.02 and 1 respectively. The outlet-pressure is set as zero Pascal with a gauge pressure. The bearing wall is set as stationary whereas the journal is set as a moving wall that is operating at a pressure of $101325 \mathrm{~Pa}$. The solution is obtained by pressure-velocity coupling with explicit relaxation factors for both pressure and momentum at 0.75 [21]. The inlet velocity is obtained from standard initialization which is computed from the inlet-pressure. The dynamic mesh condition is used to solve the flow model by providing the motion in domain boundaries in meshing zones. The results generated from the flow model help us to visualize the contour velocity and pressure profiles of airflow on a designated plane from the initial point i.e. orifice to the edge of the bearing. Based on pressure and velocity profile, the pressure distribution plots for journal and thrust bearing can be generated. The streamlined data of airflow can also be analyzed to understand the behavior of airflow within the bearing clearance. The results are calculated in terms of radial distance (r) which starts from the central axis of the orifice towards the edge of the bearing.

\section{Experimentation for fine finishing of an aerostatic bearing}

The surface roughness effects on the static performance of orifice fed aerostatic bearing are investigated experimentally by reducing roughness peaks on the bearing surface and spindle surface for both thrust and journal sides. The appropriate surface is generated by three processes namely machining, internal cylindrical grinding, and magnetorheological (MR) fluid finishing. The reason for using the MR fluid finishing process after grinding is that it can achieve nano-scale roughness values with better surface qualities as compared to single-point diamond turning (SPDT) process [22].

The surface of the spindle and the bearing shell is machined by a Turno-mill center. The material used for bearing shell is SS 316 and the spindle is of Al 2024. After the initial machining, the roughness value (Ra) of $1100 \mathrm{~nm}$ and $540 \mathrm{~nm}$ were achieved for bearing and spindle surfaces respectively. For measuring the surface roughness of the spindle and journal bearing, a surface roughness tester (Mitutoyo Surftest SJ-400) with a cut-off length of $0.25 \mathrm{~mm}$ is utilized. The roughness profiles of these surfaces are shown in Figs. 3 (a) and (b). Based on these values of surface roughness, the total load capacity of thrust and journal bearing is evaluated with respect to pressure and eccentricity.

In order to improve current performance, the stainless-steel surface of the bearing is further finished with the cylindrical grinding process. However, the aluminum spindle surface is not finished further. This is owing to the fact that the clogging of the grinding wheel is one of the major issues during the grinding of aluminum which can be minimized by using various composites [23]. Also, the machining of aluminum by turno-mill center achieved the surface roughness upto that extent which is 
experimentally determined by grinding of the aluminum alloys by various processes in the previous study [24].

Further, in cylinder grinding, the major parameters to minimize the surface roughness of the bearing shells are hardness, depth of cut, and speed. So, based on the hardness of SS316, the cutting conditions are workpiece speed is set at $120 \mathrm{rpm}$, grinding wheel speed is $1000 \mathrm{rpm}$, the longitudinal feed is 10 $\mathrm{mm} / \mathrm{s}$ and infeed is set at $0.0125 \mathrm{~mm} /$ cycle. For removal of material from work part surface in form of chips and to avoid local temperature gradients due to grinding tool, the coolant is constantly supplied. The surface roughness achieved by these working parameters is $570 \mathrm{~nm}$ on the bearing surface shown in Fig. 3(c).

The surface of the bearing and spindle is further improved by the magnetorheological finishing (MRF) process. The MRF process is used in this study to finish the non-ferromagnetic materials such as stainless steel and aluminum workpieces. In the MRF process, magnetorheological polishing (MRP) fluid plays an important role. The MRP fluid is a smart fluid that consists of the electrolytic iron particles (EIPs), polishing abrasives, and the carrier fluid [25]. Under normal conditions, the MRP fluid behaves as a Newtonian fluid, however, once the magnetic field is applied, the EIPs present in the MRP fluid get magnetized [26].

Owing to MRP fluid gets stiffened forming a columnar structure due to the upsurge in the rheological properties (viscosity and yield stress). In the MRF process, the magnetic field act as a driving force due to which the magnetic EIPs tend to move towards the higher concentration of magnetic flux (tool surface) and nonmagnetic abrasive move towards the lower concentration of the magnetic flux (work part surface) [27]. Due to this phenomenon, the MRP fluid always remains rich with the abrasives over the work part surface. Further, in the MRF process, the normal forces acting on the abrasives are low due to which a clean and damage-free surface are obtained with surface finish up to nano meter level. In order to achieve finishing of this level on the bearing internals surface and spindle outer surface, two different magnetorheological processes are used [28, 29]. For the finishing of the internal surface of the stainless-steel bearing, the permanent magnet honing tool is used [28] while for the external surface of the aluminium spindle, the electromagnet tool is used [29]. During the finishing of the internal surface of the bearings, the magnetic field is applied by the permanent magnet tool while for the external finishing of the spindle, the magnetic field is applied by the external current source. On the application of the magnetic field, the MR polishing fluid present on the magnetic tool gets stiffened in the working gap amid the tool and workpiece surfaces. Due to the simultaneous rotational and reciprocation motion of the magnetic tool the abrasive particles present in the MR polishing fluid, shear off the surface asperities from the workpiece surface leading to the smooth surface finishing. The composition of MR fluid used for this process is given in Table 3. 


\subsection{Material removal mechanism for magnetorheological finishing of the spindle and bearing}

In the present work, the magnetorheological polishing (MRP) fluid is utilized for fine finishing of the external spindle surface and internal bearing surface. The abrasive particles present is the MRP fluid responsible for shearing off the roughness asperities from the work part surface are called active abrasive particles (AAPs). In this study, the material removal from the external spindle surface and internal bearing surface takes place in two steps. Firstly, the magnetic field induce the force due to which the active abrasive particles (AAPs) present in MRP fluid penetrates on the external surface. Secondly, there is the detachment of the material from the workpiece surface in the form of microchips as the tool and the workpiece rotates simultaneously. In magnetorheological finishing (MRF) process, material removal occurs owing to the abrasion action of the AAPs over the cup surface over a time. Further, the extent of the abrasive action is dependent on the simultaneous rotation of tool and workpiece as well as the hardness of workpiece.

For the fine finishing of the external surface of the spindle magnetorheological finishing process with electromagnetic rotating tool core is used [29]. In this process, the tool core is rotated and reciprocated simultaneously along with the oppositely rotating workpiece as depicted in Fig. 4. On the application of the magnetizing current, the magnetic field is induced on the electromagnetic tool surface. Due to the induced magnetic field on the electromagnetic tool surface, magnetic iron particles move towards the tool surface and push the non-magnetic abrasive particles with levitation force towards the low magnetic field i.e., external spindle surface. Applied levitation force pushes the active abrasive particles with magnetic force $\left(F_{n e}\right)$ which indents the active abrasives onto the external surface of the spindle as shown in Fig. 4. The magnetic force produced during the process depends on the current intensity. With the rise in current, the concentration of magnetic flux upsurge, resulting in an increase of the indentation force. The magnetic force acting over a single magnetic iron particle in the presence of the magnetic field towards external spindle surface $\left(F_{n e}\right)$ can be evaluated by using Eq. (7) [26].

$F_{n e}=m_{i} \mu_{0} \chi_{m} B \nabla B$

where the mass of the electrolytic iron particle is $\mathrm{m}_{\mathrm{i}}$ in $\mathrm{kg}$. Mass susceptibility of the iron particle is denoted as $\chi_{\mathrm{m}}$ in $\mathrm{m}^{3} / \mathrm{kg}$. The magnitude of the magnetic field is denoted as $\mathrm{B}$ in $\mathrm{A} / \mathrm{m}$. The gradient of the magnitude in the magnetic field is denoted as $\nabla \mathrm{B}$. The magnetic permeability in free space is denoted as $\mu_{0}$ in $\mathrm{H} / \mathrm{m}$.

Further, owing to the rotary speed of the rectangular tool core, the AAPs applies the tangential cutting force $\left(F_{t c e}\right)$ over the external spindle shaft. Fig. 4 shows the direction of the tangential cutting force $\left(F_{t c e}\right)$ which is tangential to the rotary speed of the active abrasive towards external spindle surface. The $F_{\text {tce }}$ is evaluated using Eq. (8). 
$F_{t c e}=m_{a} r \omega^{2}$

where $\mathrm{m}_{\mathrm{a}}$ is the mass of the abrasive particle in $\mathrm{kg}$, the radius of the rotation of the AAP is denoted as $\mathrm{r}$ in $\mathrm{m}$ and the angular velocity of the active abrasive is denoted as $\omega$ in $\mathrm{rad} / \mathrm{s}$.

Further, owing to the reciprocatory movement of the rotating rectangular tool core, an axial force $\left(F_{a e}\right)$ is applied on the active abrasive towards external spline surface. This $F_{a e}$ is acted in the parallel direction of the reciprocatory movement of the rectangular tool core tip and calculated by Eq. (9) [28]. $F_{a e}=\tau\left(A_{b}-A_{g}\right)$

where the shear strength of spline shaft tooth is denoted as $\tau$ in $\mathrm{N} / \mathrm{m}^{2}$. The area of the active abrasive is denoted as $A_{b}$ in $\mathrm{m}^{2}$. The indentation area by active abrasive into the spline shaft tooth surface is denoted as $\mathrm{A}_{\mathrm{g}}$ in $\mathrm{m}^{2}$.

The indentaion deppth of AAPs on the external spindle workpiece surface depends on the magnitude of the magnetic normal force $\left(F_{n e}\right)$. The axial force $\left(F_{a e}\right)$ due to the tool core feed rate and the tangential force $\left(F_{t c e}\right)$ due to tool rotation are accountable for material removal from the external surface of the spindle. Further, in the present work, the external spindle surface is rotated in the opposite direction to that of the tool core as depicted in Fig. 4. Owing to which, the tangential force due to workpiece $\left(F_{t w e}\right)$ rotation acts over the workpiece rotation along with the tangential force due to tool core rotation $\left(F_{\text {tce }}\right)$ in the same direction as shown in Fig. 4. These two forces get added to result in net cutting tangential finishing force $\left(F_{t c}\right)$ towards external spindle surface and can be calculated by using Eq. (10).

$F_{t c}=F_{t c e}+F_{t w e}$

The repetitive simultaneous action of the net cutting tangential finishing force and axial force over the asperities forms the helical path over the workpiece surface (Fig. 4) which contributes to the material removal from the external spindle surface.

Further for the fine finishing of the internal surface of bearings, the rotational magnetorheological (RMR) honing process is used [28]. In the MRH process, the permanent magnetorheological honing (MRH) tool is used. For the fine finishing of the internal bearing surface, the MRH tool and bearing workpiece are rotated in the opposite direction simultaneously as depicted in Fig. 5. In the R-MR honing process, the simultaneous rotational and reciprocation movement of the active abrasive particles (AAPs) over the workpiece surface leads to the abrasion action. Moreover, owing to the simultaneous rotation to the tool and internal bearing along with reciprocation of the tool, the AAPs tend to follow the helical path as shown in Fig. 5. The asperities from the bearing surface get sheared off along this helical path only. The MRH tool and workpiece surface are rotated in opposite directions owing to which the length of the helical path and number of turns of the AAP on the helical path upsurges. This leads to the fine surface finish of the internal surface of the bearing. The material 
removal from the spindle and bearing is owing to the three types of the forces that act on the AAPs namely tangential shear force $\left(F_{t a n}\right)$, magnetic indentation force $\left(F_{i n}\right)$, and axial force $\left(F_{a x}\right)$. The removal of material from the internal bearing work part surface is due to different forces is depicted in Fig. 5. Initially, the EIPs get magnetized and form the columnar structure when the MRP fluid is applied over the surface of the permanent magnet of the MRH tool. The nonmagnetic active abrasive particles (AAPs) which are gripped in the EIPs chain tend to move towards the low gradient magnetic flux (B) from the high gradient of the B i.e. towards the work part surface. The stiffened columnar structure formed by the EIPs along with the AAP is on the surface of the permanent magnet MRH tool. The stiffened MR polishing fluid over the tool surface acts as a unibody these magnetic EIPs apply the magnetic indentation force $\left(F_{i n}\right)$ over the AAPs. Due to this, the AAP indents on the surface asperities present on the work part surface. The indentation of the AAPs leads to the micro ploughing of the material around the indented abrasive marks. Further, as the MRH tool rotates and reciprocates simultaneously along with the bearing workpiece rotation, the asperities get sheared off by the AAPs from the internal bearing surface. Owing to the simultaneous rotation and reciprocation of MRH tool along with bearing workpiece rotation, the AAPs experience the tangential shear force $\left(F_{\text {tan }}\right)$ and the axial force $\left(F_{a x}\right)$ as shown in the Fig. 5 The $F_{\text {tan }}$ is due to the simultaneous rotation of the tool and the bearing surface. As the tool and workpiece rotates simultaneously, the AAPs shear off the surface asperities in the tangentially as shown in Fig. 5. Further, with the simultaneous rotation of the tool and workpiece, the MRH tool also have the reciprocation motion. Owing to the reciprocation of the MRH tool, the AAP experience the axial force $\left(F_{a x}\right)$ as depicted in Fig. 5. The $F_{a x}$ helps the AAPs to shear off the asperities from the bearing surface along the axial direction. Hence, the internal bearing surface get fine finished with the combined effect of the magnetic indentation force $\left(F_{n i}\right)$ and the resultant shear force $\left(F_{\tan }\right.$ and $F_{a x}$ ) using the permanent magnetic tool. Owing to the simultaneous tool rotation and reciprocation, the AAPs from the helical path over the spindle and bearing workpieces respectively as depicted in Figs. 4 and 5. The shearing of the surface asperities by the AAPs from the work part surfaces is done repeatedly along these helical paths leading to the fine surface finishing.

\subsection{Experimental setup for the magnetorheological finishing of the spindle and bearing surfaces}

In the present study for the MR fine finishing of the external spline surface and internal bearing surface. For the finishing of the external spline surface, rectangular tip electromagnet-based MR finishing tool (Fig. 6a) is used and for internal bearing surface finishing, MR honing tool (Fig. 6b) is utilized. Two different set ups are used for MR finishing both the surfaces of the aerostatic bearing. When external surface in finished, rotating rectangular tip tool core is inserted in the electromagnetic coil (Fig.6a). For the finishing operations, three types of motions are used namely rotary motion of tool, the rotary motion of workpiece, and reciprocatory motion of tool. Further, to perform the finishing over the 
internal surface of bearing, three types of motion are used in the present work. These are the rotary motion of the magnetorheological honing (MRH) tool, the rotary motion of the bearing workpiece, and the reciprocation motion of the MRH tool as depicted in Fig. 6. In both the experimental setups, three different servo motors were used for providing the 0different motions. The servo motors are controlled using the programmable logic controller (PLC). Further, the mixture of EIPs, abrasives, and base fluid is mixed in the mixture for preparing the magnetorheological polishing (MRP) fluid. The components are mixed homogeneously for 30 to $45 \mathrm{~min}$ in mixing chamber. In the present study, the MR finishing process of the spindle and bearing surfaces are carried out based on finishing parameters which are selected from the available literature [28-30] and preliminary experimentations. For the finishing of the external spindle surface, the electromagnetic tool is used for the finishing operation (Fig. 6a). The rotational speed of the tool used in the finishing operation is $400 \mathrm{rpm}$ with a feed rate of $25 \mathrm{~mm} / \mathrm{min}$. The spindle workpiece is rotating at $100 \mathrm{rpm}$ with a clearance of $0.6 \mathrm{~mm}$ maintained between the surface of the tool and workpiece for the MRP fluid. The current used for the magnetization of the electromagnetic tool is 2 A. Further, for journal bearing internal cylindrical surface, the rotational speed of the magnetorheological honing (MRH) tool is taken as $200 \mathrm{rpm}$, the reciprocating speed of the MRH tool is taken as $70 \mathrm{~cm} / \mathrm{min}$ and the working gap is kept constant as $0.6 \mathrm{~mm}$ between the magnetic tool surface and non-ferromagnetic cylindrical stainless-steel bearing workpiece surface for the MR polishing fluid.

\section{Results and discussion}

In this work, initially, the feasibility of the designed journal and thrust bearing are studied by analysing the pressure distribution studied through CFD simulation and validated. Further, the experimentations were performed to explore the efficacy of the aerostatic bearing using three different techniques naming machining, grinding and magnetorheological finishing process.

\subsection{Analysis of newly designed aerostatic bearing}

In the present work, a novel aerostatic bearing is designed and further numerically investigated by simulation of airflow in ANSYS Fluent with the computational fluid dynamics module. The results of the velocity and pressure profile are discussed below.

\subsubsection{Velocity and pressure profiles for bearing model}

The variation in velocity and pressure within the clearance gap for the journal and thrust bearing are given in Table 4 and Table 5 respectively. As air enters into the bearing clearance through the orifice, the rapid change in flow direction and cross-section area forms a small separation bubble at the wall of the spindle surface. Due to this bubble formation, the cross-section area for the air flow decreases and velocity keeps increasing which causes the air to cross the sound velocity barrier up to c' $=0.06$ $\mathrm{mm}$ which may form shock waves in the sonic region. However, after air passes through the axial 
distance c' $=0.05 \mathrm{~mm}$, the area of the cross-section of the flow region starts to increase, thereby velocity decreases to the sub-sonic region. The formation of the sonic region in a journal bearing at a supply pressure of 3 bar and 4 bar has flow velocity less than sound velocity. So, there is no shock wave formation in the flow region. The further increase in supply pressure produces the shock waves due to high compression of air which increases the pressure in the clearance region. The velocity and pressure profiles for journal bearing and thrust bearing are shown in Figs. 7 and 8 respectively. Fig. 7(a) shows that velocity profile increases at the edge of orifice i.e., at the entry of orifice through air chamber upto clearance space $(0.05 \mathrm{~mm})$ due to a decrease in the area of cross-section. However, the pressure profile of journal bearing as shown in Fig. 7(b) reveals that the pressure decreases at the edge of the orifice i.e. at the entry of the orifice through the air chamber upto clearance space due to a decrease in the area of cross-section.

Figs. 8(a) and (b) show the velocity and pressure profiles for the thrust bearing also follow a similar trend as for the journal bearing. Due to the divergence in airflow in the clearance gap, the pressure is maximum and velocity is minimum at $c^{\prime}=0$. As air flows in the direction towards the edge of the bearing, velocity keeps on decreasing while pressure is normally distributed within the clearance gap. The variation in velocity and pressure profiles in the thrust bearing is similar to the variation in velocity and pressure profiles in the journal bearing in the orifice section. But due to flat clearance gap and recess shape in the thrust bearing, the pressure is maintained upto a larger value of c' which also increases the load carrying capacity.

Further, the variation in pressure distribution within the clearance gap for journal bearing is shown in Fig. 9(a). It shows that the dimensionless pressure varies from 0.4 to 0.6 which is closest to the optimum range as given in literature [31]. As air enters the bearing clearance through the orifice, there is a rapid change in flow direction and area of cross-section forms a small separation bubble at the wall of spindle surface. Due to this bubble formation, the area of the cross-section for the airflow decreases and velocity keeps increasing which causes the air to cross the sound velocity barrier upto $\mathrm{r}=0.06 \mathrm{~mm}$ which may form shock waves in the sonic region.

After air passes through the axial distance of $0.05 \mathrm{~mm}$, the area of the cross-section of the flow region starts to increase, thereby velocity decreases to the sub-sonic region. The formation of the sonic region in a journal bearing at a supply pressure of 3 bar and 4 bar has flow velocity less than sound velocity (Fig. 9b). So, there is no shock wave formation in the flow region. The further increase in supply pressure produces the shock waves due to high compression of air which increases the pressure in the clearance region. The pressure distribution in the aerostatic thrust bearing is due to the small clearance gap. The pressure variations in thrust bearing are mainly due to the vortex flows at the edge of the orifice which decreases the pressure of air film. 
To minimize this effect, the geometric corrections in shape and size of the orifice should be analyzed. In the study, this factor is considered to minimize the effect of vortex flow by using the recess shape at the outlet of the orifice. So, the numerical study shows that the pressure distribution for the thrust bearing is enhanced by using recess shape as outlet compensation. Fig. 9(b) shows the pressure distribution curves in the thrust bearing at various supply pressure along with the radial distance. The current numerical study is compared with the literature to validate the design of the aerostatic journal and thrust bearings. The pressure distribution graphs and velocity profile of the current study are compared with studies performed by the researchers as shown in Figs. 10(a) and (b). The comparison of the relation between bearing parameters with previous studies shows the following points which validate the current design study

- For journal bearing, the value of dimensionless pressure at various supply pressures for axial and circumferential directions in both the studies are almost similar for both orifice and air film gap. The dimensionless pressure curve (Fig. 9a) shows the improvement in pressure ratios as the values of dimensionless pressure are found in between 0.35 to 0.6 as compared to the previous study as shown in Fig. 10(a) [32].

- For thrust bearing, the pressure distribution curve in the current study (Figure 9b) shows a similar relation between the dimensionless parameters generated in numerical simulation. The pressure curve evaluated in this study shows the fluctuation due to shock waves generated by the high velocity of air. These considerations are neglected in previous studies as shown in Fig. 10(b) [33].

- The numerical simulation is given in the literature also shows the bubble formation at the wall of the spindle surface which is the major reason for high velocity and low-pressure regions. In previous studies, this region is formed when the supply pressure is greater than or equal to 3 bar. Due to consideration of geometrical parameters such as orifice length and orifice diameter, this region is eliminated up to 4 bar pressures in journal bearing. But the thrust bearing shows the similar region under the supply pressure of 3 bar.

\subsection{Effect of the surface roughness on the load bearing of the journal and thrust bearings}

In the present work, the processing time for each finishing cycle for both bearing and spindle surfaces is kept $30 \mathrm{~min}$ and the roughness value is evaluated after each finishing cycle. After each finishing cycle, the MR polishing fluid is changed and fresh fluid is applied over the surface of the magnetic tool. this is done so that the edges of the abrasive particles remain fresh after each finishing cycle. The total MR finishing on the bearing and spindle is done for $90 \mathrm{~min}$ each. The MR fluid finishing removes the roughness peaks which are left after internal grinding of a cylindrical workpiece and the machining 
of spindle surface by turno-mill center. The change in the average surface roughness of the spindle and bearing surface after being processed by the present MR finishing after $30 \mathrm{~min}$ is found as $55.55 \%$ $(540 \mathrm{~nm}$ to $240 \mathrm{~nm}$ ) and $59.64 \%$ (570 to $230 \mathrm{~nm}$ ) respectively. Further, in next $30 \mathrm{~min}$ of the finishing cycle, the reduction in surface roughness was observed as $45.83 \%$ (240 to $130 \mathrm{~nm}$ ) for spindle and $63.04 \%$ (230 to $85 \mathrm{~nm}$ ) for bearing. After $60 \mathrm{~min}$ the removal rate becomes slow. The minimum average surface roughness values were achieved as $80 \mathrm{~nm}$ for spindle and $45 \mathrm{~nm}$ for bearing surface after 90 min of the surface finishing. The surface roughness profiles of the final finished spindle and bearing surface are shown in Fig. 11(a) and (b) respectively. Further the final finished surfaces of the spindle and bearing are depicted in Fig. 11(c).

In the present study, the effect of surface roughness on the load-carrying capacity of the aerostatic journal and thrust bearing is analysed by comparison of load-carrying capacity at various finished surfaces (machined, grinding, and MR finishing). The values of maximum load-carrying capacity for the journal and thrust bearings are determined for the initial ground and final finished surface. The experimental setup includes the air supply components and the testing equipment such as displacement gauge, dial gauge and push-pull dynamometer as shown in Fig.12(a). Displacement gauge is used to measure travel range between where an object is and a reference position.

A dial gauge is a precision measurement commonly used to measure machined parts for tolerances. Push-Pull Dynamometer is a convenient muscle strength device which is used to measure the ability of component to push or pull an object with a particular degree of force. Further, the radial and axial loads are applied by a dynamometer and the corresponding value of the displacement in the spindle is calculated.

In order to calculate the radial and axial load carrying capacity, the positions for placing the dynamometer and displacement gauge are different for the journal and thrust bearing as shown in Fig. $12 \mathrm{~b}$ and $\mathrm{c}$ respectively. Initially, the machined surfaces of bearing $\left(\mathrm{R}_{\mathrm{a}}=1100 \mathrm{~nm}\right)$ and spindle $\left(\mathrm{R}_{\mathrm{a}}=\right.$ $540 \mathrm{~nm}$ ) are assembled to evaluate the load-carrying capacity at the various supply pressure as depicted in Fig. 12. After the calculation of load data on the machined surface, the internal grinding surface of the bearing $\left(R_{a}=570 \mathrm{~nm}\right)$ is assembled to calculate the same results as calculated for the machined surface. At last, the final finished surface which is processed by MR fluid finishing technique $\left(R_{a}=45\right.$ $\mathrm{nm}$ for bearing surface and $\mathrm{R}_{\mathrm{a}}=90 \mathrm{~nm}$ for spindle surface) is used in the calculation of the same data as calculated before. These results are compared to validate the effect of average surface roughness on the load-carrying capacity of the aerostatic bearing.

The average increase in load carrying capacity $\left(\Delta L_{\text {avg }}\right)$ due to the effect of surface roughness for a specific value of spindle displacement is calculated by Eq. (11). 


$$
\Delta L_{\mathrm{avg}}=\frac{\sum_{i=3 \text { to } 6 \text { bar }}\left[\left(R_{\text {improved }}\right)_{i}-\left(R_{\text {initial }}\right)_{i}\right]}{\text { Number ofvariations in pressure }}
$$

where $R_{\text {improved }}$ is the final value of average surface roughness achieved by internal grinding then it is further achieved by MR fluid finishing process and $R_{\text {initial }}$ is the average surface roughness value of machined surface. the pressure is varied from 3 bar to 6 bar (i.e., 4 variations).

Initially, Eq. (11) is used to find the comparison of grinding surface with initial machined surface based on the average increase in load capacity for grinding surface. After that, Eq. (11) is further used to analyzed for MR finished surface to show the change in load carrying capacity on the further reduction in average roughness value. These comparisons amid machined, grinding, and MR finished surface provide the total effect of surface roughness on both journal and thrust bearings. The test is performed for journal bearing at an initial supply pressure of 3 bar with the bearing clearance of 30 $\mu \mathrm{m}$. The supply pressure is kept constant until the maximum radial load is achieved at $1 \mu \mathrm{m}$ to $5 \mu \mathrm{m}$ displacement of the spindle is being evaluated as depicted in Fig. 12. Similarly, the load capacity at each value of displacement is evaluated at a supply pressure of 4 bar, 5 bar, and 6 bar respectively. This data on load-carrying capacity generates the load-displacement relation at various supply pressure as shown in Fig. 13. The experimental data is evaluated for three types of bearing surfaces namely machined surface, internal grinding surface, and MR finished surface. From Fig. 13, it can be revealed that for the journal bearing, as the pressure increases from 3 to 6 bar across the displacement $(1-5 \mu \mathrm{m})$, the maximum load bearing capability is for MR finished bearing surface followed by initial grinded surface and minimum for machined surface. this signifies that with the decrease in surface roughness, the load bearing carrying capacity of the journal bearing increases.

Further, the first comparison is made between the machined and internal grinding surface based on Eq. (11). The load-deflection data at various pressures values (3-6 bar) shows the variation in the value of the radial load on the machined and internal grinding surface of the bearing at a radial deflection of 5 $\mu \mathrm{m}$. For a supply pressure of 3 bar varies from load varies from $0.15 \mathrm{~N}$ to $0.3 \mathrm{~N}$ (Fig.13a). With the increase in supply pressure from 3 bar to 4 bar, the variation becomes $0.75 \mathrm{~N}$ to $1 \mathrm{~N}$ (Fig. 13b). Similarly, when pressure is increased to 5 bar and 6 bar, the variation in load capacity is evaluated as $1.25 \mathrm{~N}$ to $1.45 \mathrm{~N}$ (Fig. 13c) and $2.1 \mathrm{~N}$ to $2.2 \mathrm{~N}$ (Fig. 13d) respectively. Hence, the approximate value of the average increase in load-carrying capacity for $5 \mu \mathrm{m}$ is found to be $0.14 \mathrm{~N}$ (Fig. 14). This value shows the effect of surface roughness on maximum load-carrying capacity at $5 \mu \mathrm{m}$ displacement in journal bearing achieved by internal cylindrical grinding. Similarly, the average increase in load carrying capacity for journal bearing displacement of $1 \mu \mathrm{m}$ to $4 \mu \mathrm{m}$ is calculated as $0.075 \mathrm{~N}, 0.096 \mathrm{~N}$, $0.11 \mathrm{~N}$ and $0.12 \mathrm{~N}$ respectively (Fig. 14). These variations show the effect of surface roughness on load-carrying capacity when the surface roughness is improved by the internal grinding technique. 
Further, the comparison between the machined surface and MR finished surface is made to evaluate total variation in load carrying capacity. Based on Eq. (7), the values of $\Delta \mathrm{L}_{\mathrm{avg}}$ at various spindle displacement from $1 \mu \mathrm{m}$ to $5 \mu \mathrm{m}$ are found to be $0.163 \mathrm{~N}, 0.198 \mathrm{~N}, 0.218 \mathrm{~N}, 0.233 \mathrm{~N}$, and $0.268 \mathrm{~N}$ respectively (Fig. 14). These comparisons for average increment in load carrying capacity due to improvement in surface roughness are shown in Fig. 14. This comparison shows the improvement in radial load-carrying capacity by reducing the surface roughness by internal grinding and MR finishing process. This is because the initial ground surface has a low concentration area and higher roughness peaks. As a result, the load bearing ability of the surface decreases. However, after the MRF, the asperities present on the surface gets flatten significantly, owing to which the concentration area of the surface upsurges. Due to this, the load bearing capability of the surface upsurges.

Further, the testing setup for thrust bearing is shown in Fig. 12(c). The initial supply pressure is 3 bar which is maintained until the maximum axial load acting on the spindle at the displacement of $1 \mu \mathrm{m}$ to $5 \mu \mathrm{m}$ is being evaluated. These values of axial load are evaluated after improving surface characteristics of bearing and spindle at various supply pressure which varies from 3 bar to 6 bar. Based on experimental results for the initial machined surface to MR fluid finished surface, the relation between load acting on thrust bearing and displacement in the spindle is evaluated with variation in pressure is up to 6 bar as shown in Fig. 15. The effect of surface roughness on thrust bearing is determined by the change in average load capacity $\left(\Delta L_{\mathrm{avg}}\right)$ using Eq. (7) at the displacement of $1 \mu \mathrm{m}$ to $5 \mu \mathrm{m}$.

The variation in load carrying capacity by reducing average surface roughness by internal grinding and MR finishing process are compared to evaluate the average increase in load for each surface improvement technique. Firstly, the effect of the internal grinding surface is evaluated by comparing axial load values with a machined surface. Based on Eq. (7), $\Delta L_{\mathrm{avg}}$ at the spindle displacement of $1 \mu \mathrm{m}$ is calculated as $0.8 \mathrm{~N}$ (Fig. 16). Similarly, for $2 \mu \mathrm{m}, 3 \mu \mathrm{m}, 4 \mu \mathrm{m}$ and $5 \mu \mathrm{m}$ of spindle displacement, the value of $\Delta L_{\mathrm{avg}}$ is found to be $0.875 \mathrm{~N}, 0.9 \mathrm{~N}, 0.963 \mathrm{~N}$ and $1.04 \mathrm{~N}$ respectively (Fig. 16). These values represent the average increase in axial load at different values of spindle displacement due to reduction in average surface roughness on the internal grinding surface. Similarly, the average load variation is evaluated by the comparison of the axial loads at the machined surface and MR fluid finished surface. Further reduction in surface roughness by MR fluid finishing show the variation in axial load up to $2 \mathrm{~N}$ (Fig. 16). The values of $\Delta L_{\text {avg }}$ determined at various spindle displacement which varies from $1 \mu \mathrm{m}$ to $5 \mu \mathrm{m}$ are found to be $1.575 \mathrm{~N}, 1.65 \mathrm{~N}, 1.7 \mathrm{~N}, 1.825 \mathrm{~N}, 2.0 \mathrm{~N}$ respectively. The average increase in axial for both the surface finishing techniques are shown in Fig. 13. Thus, the overall results show the improvement in load carrying capacity of the aerostatic journal and thrust 
bearings after the MR finishing for its better functional performance in precision applications in drives of production machines where the friction and surface properties are the major parameters of performance and efficiency.

\section{Conclusions}

The effect of surface roughness on load carrying capacity of the designed bearing are evaluated experimentally. Three different types of the bearing surfaces are used namely initial machined surface, cylinder grinding surface and the MR finished surface. On the basis of the obtained results, the following conclusions are drawn.

- For journal bearing, the current study reveals the improvement in pressure ratios which are within the range of 0.4 to 0.6 . This range is closest to the required optimum range of pressure ratios i.e. from 0.35 to 0.6 which reveals the improvement in pressure distribution in the present journal bearing.

- For thrust bearing, the pressure distribution curve reveals that there is enhancement in pressure within the clearance gap. Also, by using recess at end of orifice section, the pressure distribution in the direction of radial distance gets improved.

- In the present study, the region of pressure distribution extends upto $0.05 \mathrm{~mm}$ which thereby improves the pressure at each domain within the clearance gap. But the numerical simulation given in previous studies showed the bubble formation at the wall of spindle surface which was the major reason for high velocity and low-pressure regions.

- The load carrying capacity of journal bearing gets increased by $0.163 \mathrm{~N}, 0.198 \mathrm{~N}, 0.218 \mathrm{~N}$, $0.233 \mathrm{~N}$ and $0.68 \mathrm{~N}$ at the spindle displacement of $1 \mu \mathrm{m}$ to $5 \mu \mathrm{m}$ with the decreased in surface roughness value of $0.045 \mu \mathrm{m}$ at bearing surface and $0.08 \mu \mathrm{m}$ at spindle surface after the present MR finishing technique.

- The load carrying capacity of thrust bearing gets increased by $1.575 \mathrm{~N}, 1.65 \mathrm{~N}, 1.7 \mathrm{~N}, 1.825 \mathrm{~N}$ and $2.0 \mathrm{~N}$ at the spindle displacement of $1 \mu \mathrm{m}$ to $5 \mu \mathrm{m}$ with the decreased in surface roughness 
value of $0.045 \mu \mathrm{m}$ at bearing surface and $0.08 \mu \mathrm{m}$ at spindle surface after the present $\mathrm{MR}$ finishing technique.

- The results determined in the improvement of load carrying capacity of the aerostatic journal and thrust bearings show the better functional performance of the designed bearings. Thus, the present designed aerostatic bearing is effective for its precision applications in drives of production machines where the friction and surface properties are the major parameters of performance and efficiency.

\section{Acknowledgment}

We gratefully thank the technical assistance in manufacturing and lab sections of research and development center, Ludhiana, India for providing attention on critical areas in precise manufacturing and testing of the aerostatic bearing.

\section{Nomenclature}

$\begin{array}{ll}\mu & \text { dynamic viscosity of fluid }(\mathrm{Pa} . \mathrm{S}) \\ v_{i}, v_{j}, v_{k} & \text { velocity component in direction of } \mathrm{i}-, \mathrm{j} \text { - and k-axis } \\ x_{i}, x_{j}, x_{k} & \text { coordinate component of } \mathrm{i}-, \mathrm{j} \text { - and k-axis } \\ P & \text { density of fluid }\left(\mathrm{kg} / \mathrm{m}^{3}\right) \\ u, v, w & \text { scaler valued function in } \mathrm{x}, \mathrm{y}, \text { and } \mathrm{z} \text {-direction } \\ P & \text { pressure of fluid (bar) } \\ H & \text { fluid film thickness }(\mu \mathrm{m}) \\ V_{i n j} & \text { velocity of fluid injection }(\mathrm{m} / \mathrm{s}) \\ d_{o} & \text { outside diameter of bearing }(\mathrm{mm}) \\ \varepsilon & \text { eccentricity ratio } \\ L, D & \text { length and diameter of bearing }(\mathrm{mm})\end{array}$




\section{Declarations}

Availability of data and material: The authors confirm that material supporting the findings of this work is available within the article.

Authors Contributions: Karan Singh Jamwal- Investigation and methodology. Kunal Arora- review and editing. Sunil Kumar Paswan - review and editing. Anant Kumar Singh- supervision, writing review \& editing.

Competing interest: The authors declare that they have no competing interests.

Ethical approval: The article follows the guidelines of the Committee on Publication Ethics (COPE) and involves no studies on human or animal subjects.

Consent to participate: Not applicable. The article involves no studies on humans.

Consent to publish: Not applicable. The article involves no studies on humans.

Funding: Not applicable.

\section{References}

[1] Hsia YT, Domoto GA (1983) An experimental investigation of molecular rarefaction effects in gas lubricated bearings at ultra-low clearances. J Lub Technol 105:120-129.

[2] Li Y, Ding H (2007) Influences of the geometrical parameters of aerostatic thrust bearing with pocketed orifice-type restrictor on its performance. Tribol Int 40:1120-1126.

[3] Chen YS, Chiu CC, Cheng YD (2010) Influences of operational conditions and geometric parameters on the stiffness of aerostatic journal bearings. Prec Eng 34:722-734.

[4] Kassab SZ, Noureldeen EM, Shawky MA (1997) Effects of operating conditions and supply hole diameter on performance of rectangular aerostatic bearing. Tribol Int 30:533-545.

[5] Lin WJ, Khatait JP, Lin W et al (2006) Modelling of an orifice-type aerostatic thrust bearing. 9th Int. Conf. on Control, Automation, Robotics and Vision. IEEE 2006, 1-6.

[6] Müller C, Greco S, Kirsch B et al (2017) A finite element analysis of air bearings applied in compact air bearing spindles. Procedia CIRP 58:607-612. 
[7] Chen CH, Tsai TH, Yang DW et al (2010) The comparison in stability of rotor-aerostatic bearing system compensated by orifices and inherences. Tribol Int 43:1360-1373.

[8] Chen XD, He XM (2006) The effect of the recess shape on performance analysis of the gaslubricated bearing in optical lithography. Tribol Int 39:1336-41.

[9] Dowson D, Oteri BI (1974) Proceedings of $6^{\text {th }}$ International Gas Bearing Synopsis, Ed. NG Coles, BHRA Fluid Engineering, Cranfield, England, Paper B-3.

[10] Keneke R, Mitsuya Y (1975) Proceedings of Japan Society of Lubrication Engineers International Lubrication Conference, Tokyo, Japan 295.

[11] Stout KJ, Pink EG (1980) Orifice compensated EP gas bearings: the significance of errors of manufacture. Tribol Int 13(2):105-11.

[12]Pande SS, Somasundaram S (1981) Effect of manufacturing errors on the performance of aerostatic journal bearings. Wear 66:145-156.

[13] Kwan YBP, Post JB (2000) A tolerancing procedure for inherently compensated, rectangular aerostatic thrust bearings. Tribol Int 33:581-585.

[14] Nagaraju T, Sharma SC, Jain SC (2002) Influence of surface roughness effects on the performance of non-recessed hybrid journal bearings. Tribol Int 35:467-487.

[15] Nagaraju T, Sharma SC, Jain SC (2006) Study of orifice compensated hole-entry hybrid journal bearing considering surface roughness and flexibility effects. Tribol Int 39:715-725.

[16] Sharma SC, Kushare PB (2015) Two lobe non-recessed roughened hybrid journal bearing - A comparative study. Tribol Int 83:51-68.

[17] Zhang SJ, To S, Wang HT (2013) A theoretical and experimental investigation into five-DOF dynamic characteristics of an aerostatic bearing spindle in ultra-precision diamond turning. Int $\mathbf{J}$ Mach Tool Manufac 71:1-10.

[18]Dal A, Karaçay T (2016) Effects of the surface roughness on the dynamics of a rotor supported by aerostatic bearing. Proceedings of the WCE 2:1-6. 
[19] Launder BE, Spalding DB (1972) Lectures in Mathematical Models of Turbulence. Academic Press, London, England.

[20] Sedrez, TA, Shirzazi SA, Rajkumar YR et al (2019) Experiments and CFD simulations of erosion of a 90 elbow in liquid-dominated liquid-solid and dispersed-bubble-solid flows. Wear 426:570580.

[21] Morosi S, Santos IF (2011) On the modeling of hybrid aerostatic gas journal bearings. J Eng Tribol 225:641-53.

[22]Dumas P, Goloni D, Tricard M (2005) Improvement of figure and finish of diamond turned surfaces with magneto-rheological finishing. Proc. SPIE 5786, WDTM; 9.

[23]Ilio AD, Paoletti A, Tagliaferri V et al (1996) An experimental study on grinding of silicon carbide reinforced aluminium alloys. Int J Mach Tool Manufac 36:673-85.

[24] Novak M, Napestkova N, Ruzicka L (2012) New ways in aluminium alloys grinding. Key Eng Mater 496:132-137.

[25] Saraswathamma K, Jha S, Rao PV (2015) Experimental investigation into ball end magnetorheological finishing of silicon. Prec Eng 42:218-223.

[26] Arora K, Singh AK (2020) Magnetorheological finishing of UHMWPE acetabular cup surface and its performance analysis. Mater Manufac Process 35(14):1631-1649.

[27] Yadav RD, Singh AK, Arora K (2020) Parametric analysis of magnetorheological finishing process for improved performance of gear profile. J Manufac Process 57: 254-267.

[28] Grover V, Singh AK (2017) A novel magnetorheological honing process for nano-finishing of variable cylindrical internal surfaces. Mater Manufac Process 32(5):573-580.

[29] Singh M, Singh A, Singh AK (2018) A rotating core-based magnetorheological nano-finishing process for external cylindrical surfaces. Mater Manufac Process 33(11):1160-1168.

[30] Singh M, Singh AK (2020) Magnetorheological finishing of grooved drum surface and its performance analysis in winding process. Int J Adv Manuf Technol 106(7-8): 2921-2937. 
[31] Powell JW (1970) Design of aerostatic bearing. Brighton: Machinery Publishing.

[32] Du J, Zhang G, Liu T, To S (2014) Improvement on load performance of externally pressurized gas journal bearings by opening pressure-equalizing grooves. Tribol Int 73:156-166.

[33] Zhou Y, Chen X, Cai Y et al (2018) Measurement of gas pressure distribution in aerostatic thrust bearings using pressure-sensitive film. Tribol Int 120:9-15. 


\section{Table 1}

Geometric parameters and operating parameters of journal bearing.

$\begin{array}{ll}\text { Bearing length (L) } & 39 \times 10^{-3} \mathrm{~m} \\ \text { Bearing diameter (D) } & 25 \times 10^{-3} \mathrm{~m} \\ \text { Bearing length to diameter ratio (L/D) } & 1.56 \\ \text { No of column of feeding orifice } & 2 \\ \text { No of orifice in each column } & 4 \\ \text { Supply pressure (p } \mathrm{p}_{\mathrm{s}} \text { ) } & 0.3-0.6 \mathrm{MPa} \\ \text { Atmospheric pressure }\left(\mathrm{p}_{\mathrm{a}}\right) & 1.01325 \times 10^{5} \mathrm{~N} / \mathrm{m}^{2} \\ \text { Axial distance from bearing face to orifice } & \mathrm{L} / 3 \\ \text { Air viscosity } & 17.5 \times 10^{-6} \mathrm{Ns} / \mathrm{m}^{2} \\ \text { Gas constant }(\mathrm{R}) & 287.6 \mathrm{~J} / \mathrm{kg} \mathrm{K} \\ \text { Air density } & 1.125 \mathrm{~kg} / \mathrm{m}^{3}\end{array}$

\section{Table 2}

Geometric parameters and operating parameters of thrust bearing.

\begin{tabular}{ll}
\hline Bearing Width $(\mathrm{w})$ & $20 \times 10^{-3} \mathrm{~m}$ \\
Thrust washer outer diameter $\left(\mathrm{d}_{\mathrm{o}}\right)$ & $54 \times 10^{-3} \mathrm{~m}$ \\
Washer thickness $(\mathrm{t})$ & $3 \times 10^{-3} \mathrm{~m}$ \\
No of column of feeding orifice & 1 \\
No of orifice in each column & 6 \\
Supply pressure $\left(\mathrm{p}_{\mathrm{s}}\right)$ & $0.3-0.6 \mathrm{MPa}$ \\
Atmospheric pressure $\left(\mathrm{p}_{\mathrm{a}}\right)$ & $1.01325 \times 10^{5} \mathrm{~N} / \mathrm{m}^{2}$ \\
Air viscosity $(\mu)$ & $17.5 \times 10^{-6} \mathrm{Ns} / \mathrm{m}^{2}$ \\
Gas constant $(\mathrm{R})$ & $287.6 \mathrm{~J} / \mathrm{kg} \mathrm{K}$ \\
Air density $(\rho)$ & $1.125 \mathrm{~kg} / \mathrm{m}^{3}$ \\
\hline
\end{tabular}




\section{Table 3}

Composition of MR polishing (MRP) fluid for finishing of stainless steel and aluminum.

\begin{tabular}{|c|c|c|}
\hline \multicolumn{2}{|c|}{ Components } & Specification \\
\hline \multirow[t]{4}{*}{$\begin{array}{l}\text { MRP fluid for finishing of } \\
\text { the stainless steel }\end{array}$} & $\begin{array}{c}\text { Electrolytic iron } \\
\text { particles }\end{array}$ & 800 mesh $(18 \mu \mathrm{m}) 20$ vol. $\%$ \\
\hline & & 700 mesh $(20 \mu \mathrm{m}) 20$ vol. $\%$ \\
\hline & $\mathrm{SiC}$ abrasives & Paraffin oil: $80 \%$ + AP3 grease: $20 \%$ \\
\hline & Carrier fluid & 60 vol. $\%$ \\
\hline \multirow[t]{5}{*}{$\begin{array}{l}\text { MRP fluid for finishing of } \\
\text { the Aluminum }\end{array}$} & Iron particles & 800 mesh $(18 \mu \mathrm{m}) 20$ vol. $\%$ \\
\hline & $\mathrm{Al}_{2} \mathrm{O}_{3}$ abrasives & 1000 mesh $(15 \mu \mathrm{m}) 20$ vol. $\%$ \\
\hline & Carrier fluid & Deionized water $++\mathrm{Na}_{2} \mathrm{CO}_{3}+$ Glycerine \\
\hline & & 57.7 vol. $\%+2$ vol. $\%+$ \\
\hline & & 0.3 vol. $\%$ \\
\hline
\end{tabular}

\section{Table 4}

Variation in velocity and pressure in the journal bearing.

\begin{tabular}{|c|c|c|c|c|c|}
\hline \multirow{2}{*}{$\begin{array}{l}\text { Orifice } \\
\text { Supply } \\
\text { pressure } \\
\text { (bar) }\end{array}$} & \multirow[b]{2}{*}{$\begin{array}{l}\text { Inlet } \\
\text { velocity } \\
(\mathrm{m} / \mathrm{s})\end{array}$} & \multicolumn{3}{|c|}{ Bearing clearance } & \multirow[b]{2}{*}{$\begin{array}{l}\text { Pressure (bar) } \\
\text { at } r=0.05 \mathrm{~mm}\end{array}$} \\
\hline & & $\begin{array}{l}\text { Velocity } \\
(\mathrm{m} / \mathrm{s}) \text { at } \mathrm{r}= \\
0.06 \mathrm{~mm}\end{array}$ & $\begin{array}{l}\text { Velocity } \\
(\mathrm{m} / \mathrm{s}) \text { at } \mathrm{r}= \\
0.05 \mathrm{~mm}\end{array}$ & $\begin{array}{l}\text { Pressure } \\
\text { (bar) at } \mathrm{r}= \\
0.06 \mathrm{~mm}\end{array}$ & \\
\hline 3 & \multirow{4}{*}{188} & 232 & 122 & 1.4 & 2 \\
\hline 4 & & 242 & 140 & 1.3 & 2.2 \\
\hline 5 & & 254 & 161 & 1.2 & 2.5 \\
\hline 6 & & 270 & 183 & 1.1 & 2.8 \\
\hline
\end{tabular}




\section{Table 5}

Variation in velocity and pressure in the thrust bearing.

\begin{tabular}{|c|c|c|c|c|c|}
\hline \multicolumn{2}{|c|}{ Orifice } & \multicolumn{4}{|c|}{ Bearing clearance } \\
\hline $\begin{array}{l}\text { Supply } \\
\text { pressure } \\
\text { (bar) }\end{array}$ & $\begin{array}{l}\text { Inlet } \\
\text { velocity } \\
(\mathrm{m} / \mathrm{s})\end{array}$ & $\begin{array}{l}\text { Velocity }(\mathrm{m} / \mathrm{s}) \\
\text { at } r=0.06 \mathrm{~mm}\end{array}$ & $\begin{array}{l}\text { Velocity }(\mathrm{m} / \mathrm{s}) \\
\text { at } r=0.05 \mathrm{~mm}\end{array}$ & $\begin{array}{l}\text { Pressure } \\
\text { (bar) at } \mathrm{r}= \\
0.06 \mathrm{~mm}\end{array}$ & $\begin{array}{l}\text { Pressure (bar) } \\
\text { at } r=0.05 \mathrm{~mm}\end{array}$ \\
\hline 3 & & 244 & 115 & 1.35 & 1.6 \\
\hline 4 & & 274 & 124 & 1.3 & 2.1 \\
\hline 5 & 188 & 299 & 136 & 1.25 & 2.6 \\
\hline 6 & & 328 & 155 & 1.2 & 3.1 \\
\hline
\end{tabular}


(a)

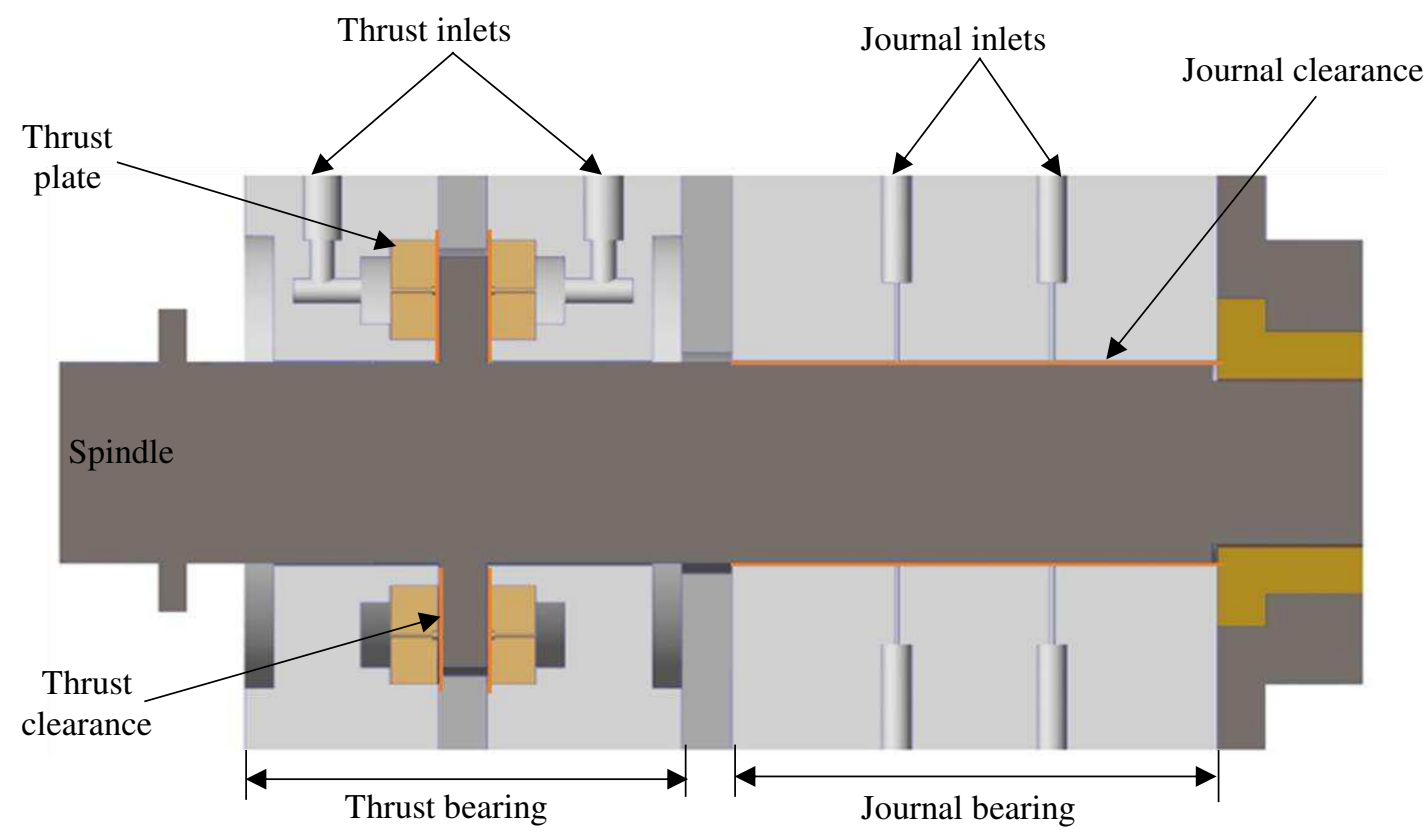

(b)

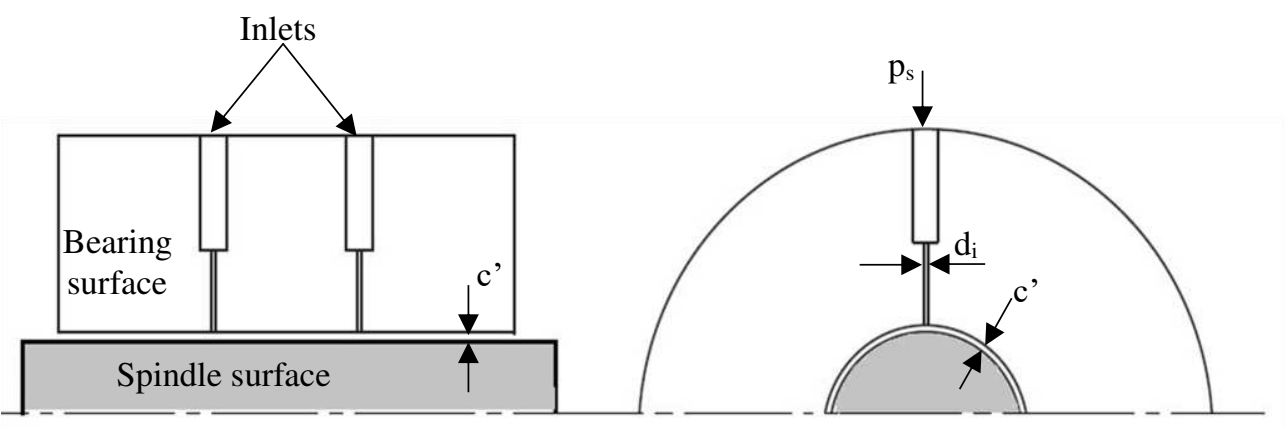

(c)

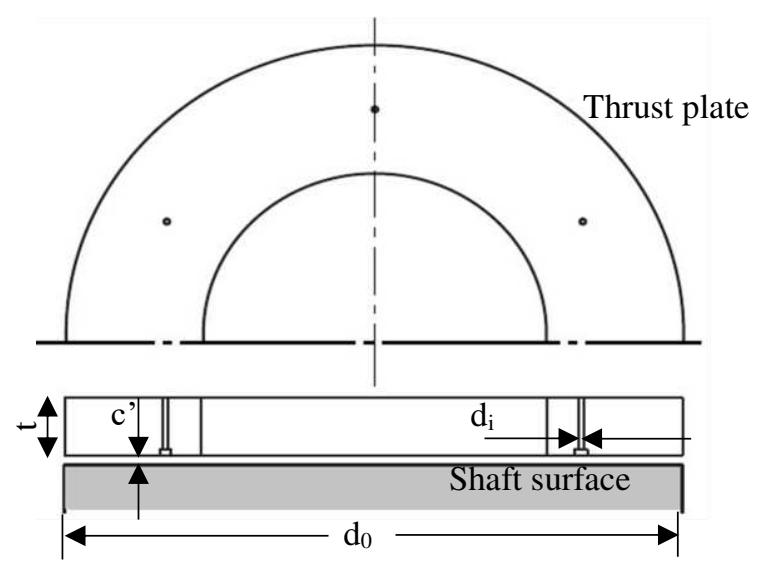

Fig. 1. (a) Assembled parts of aerostatic bearing, (b) wire-frame image of the sectional view journal bearing, and (c) wire-frame image of the sectional view of thrust plate and shaft surface. 
(a)

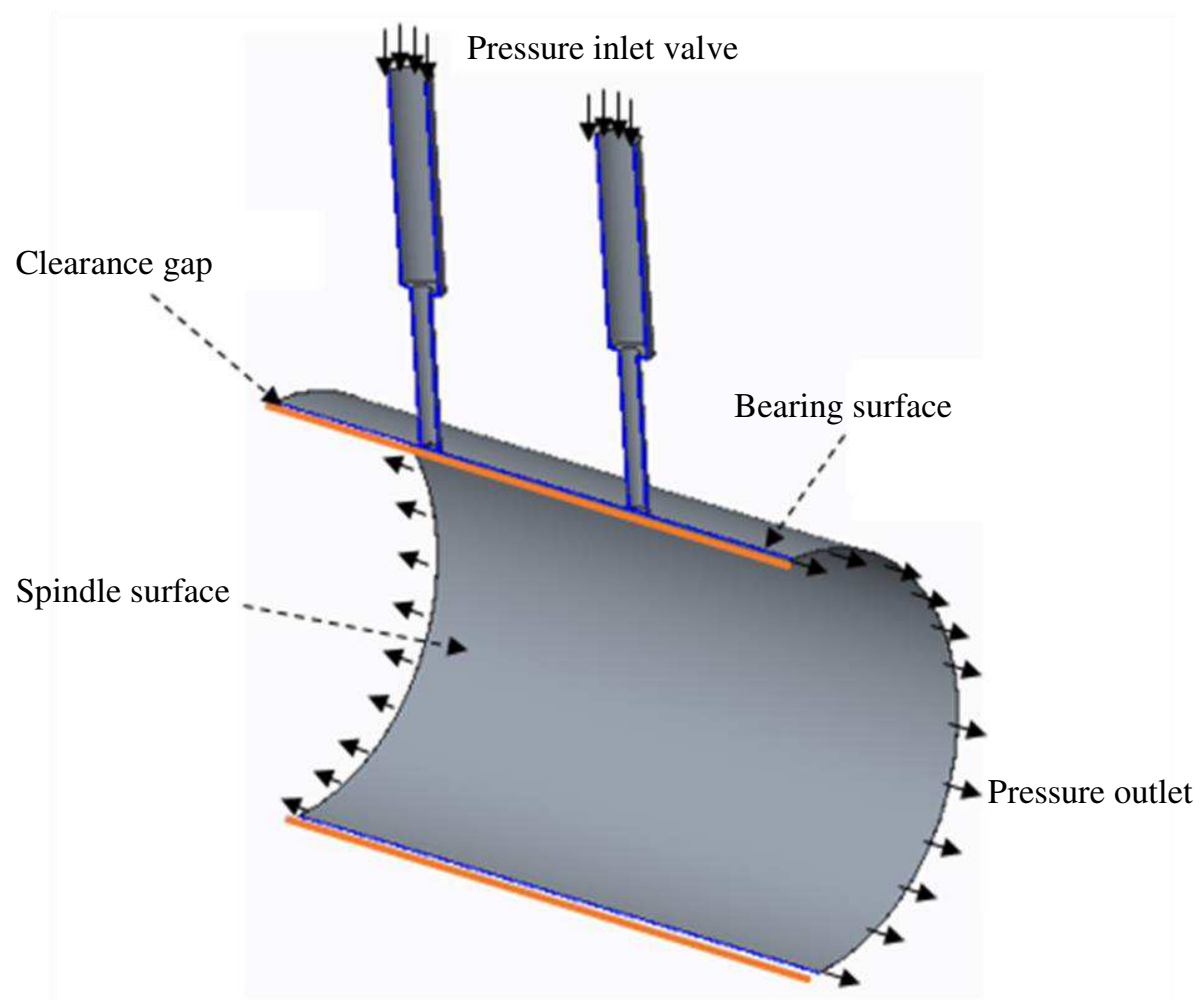

(b)

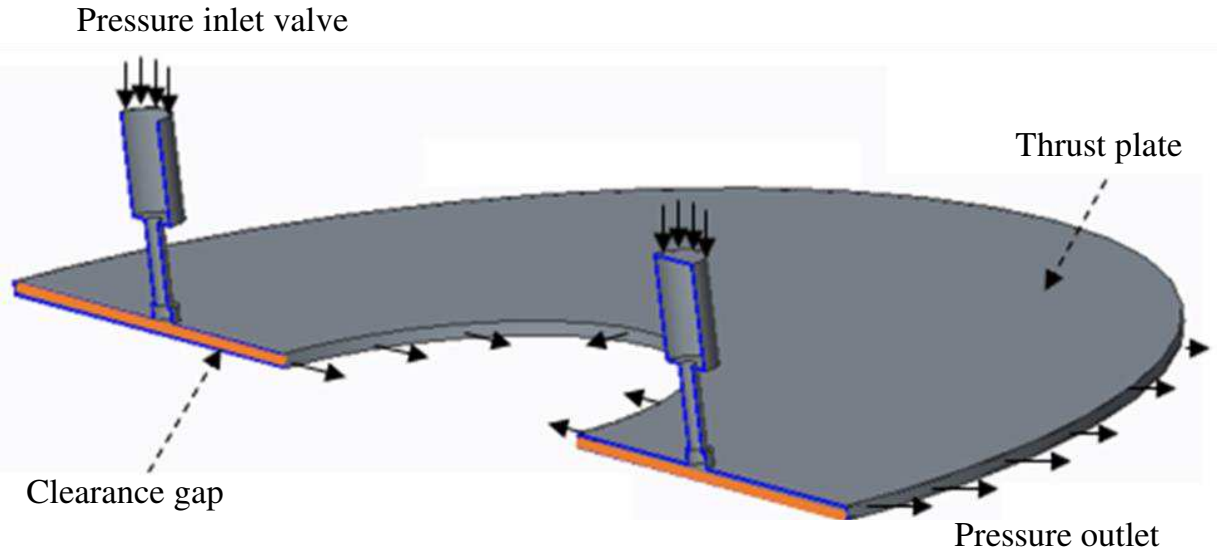

Fig. 2. Working of (a) journal bearing, and (b) thrust bearing during simulation in CFD model. 
(a)

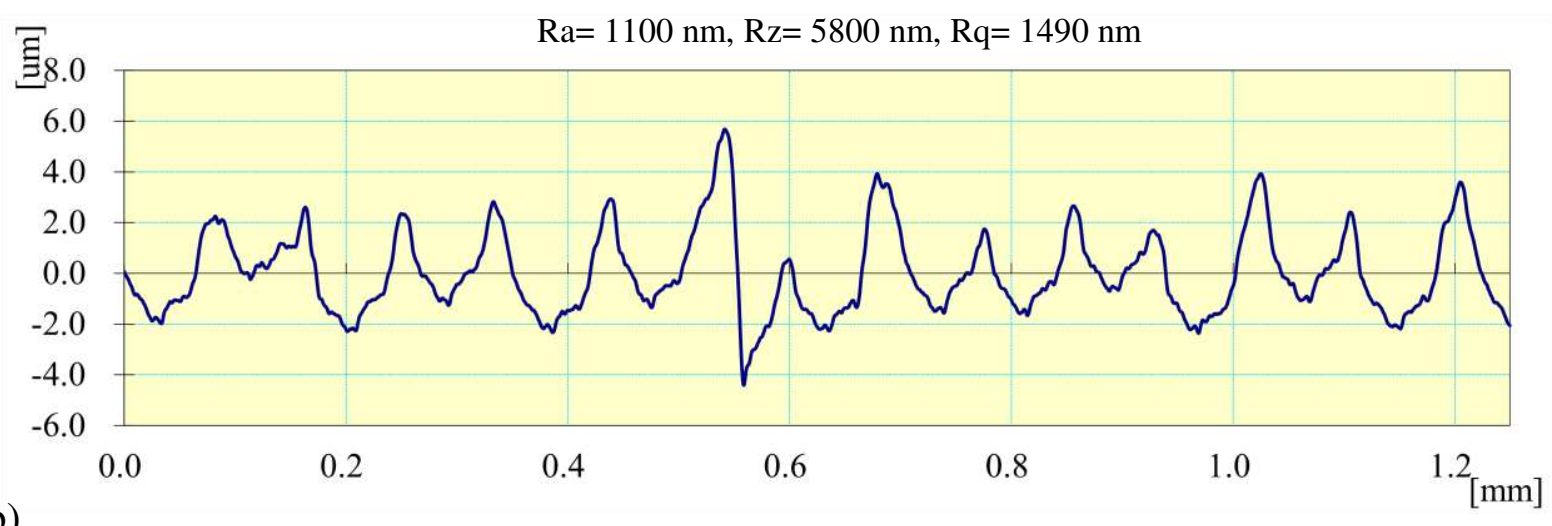

(b)

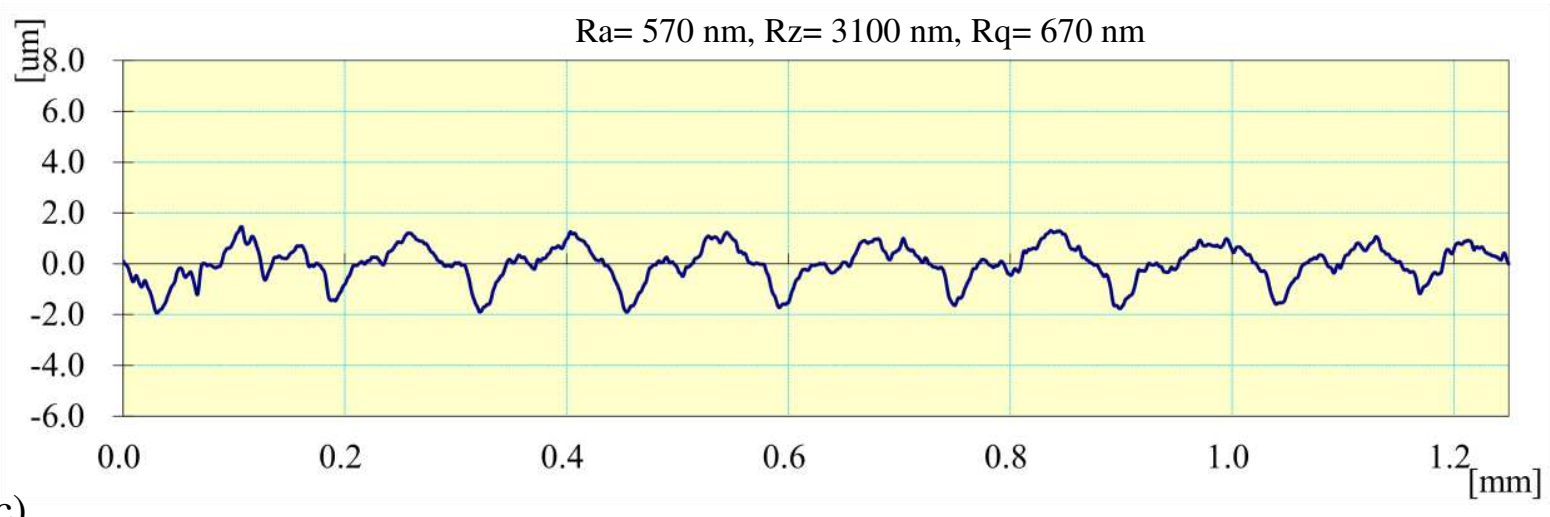

(c)

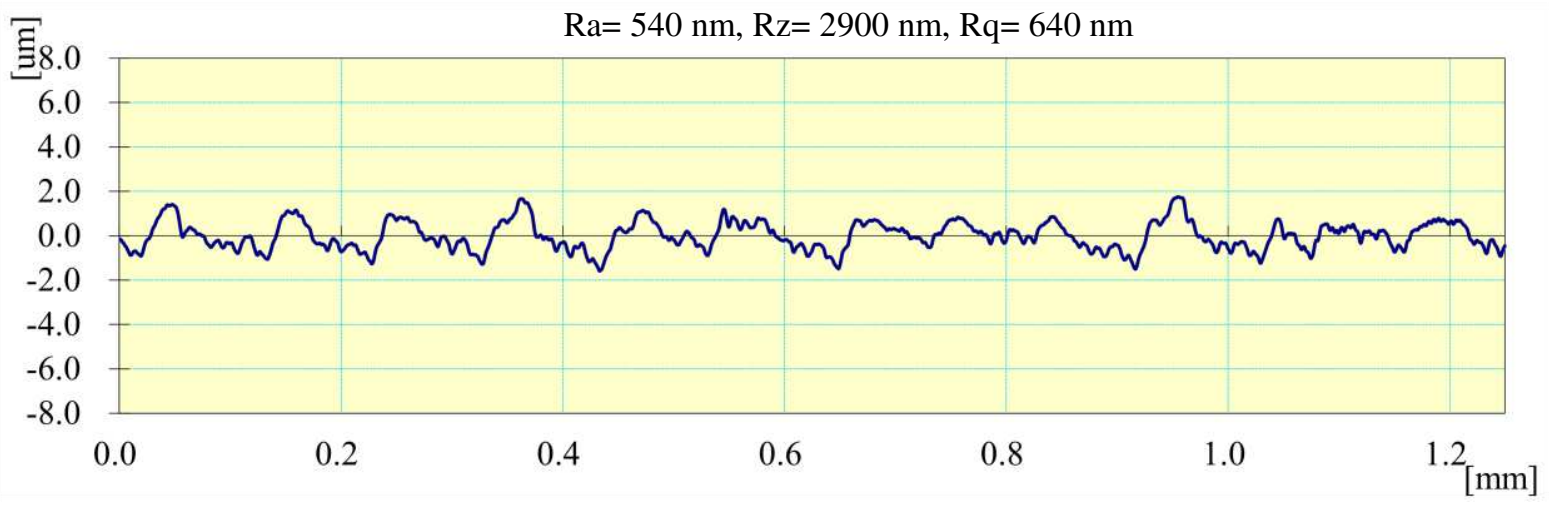

Fig. 3. Roughness profile of (a) machined bearing internal surface, (b) ground bearing internal surface, and (c) machined spindle surface. 


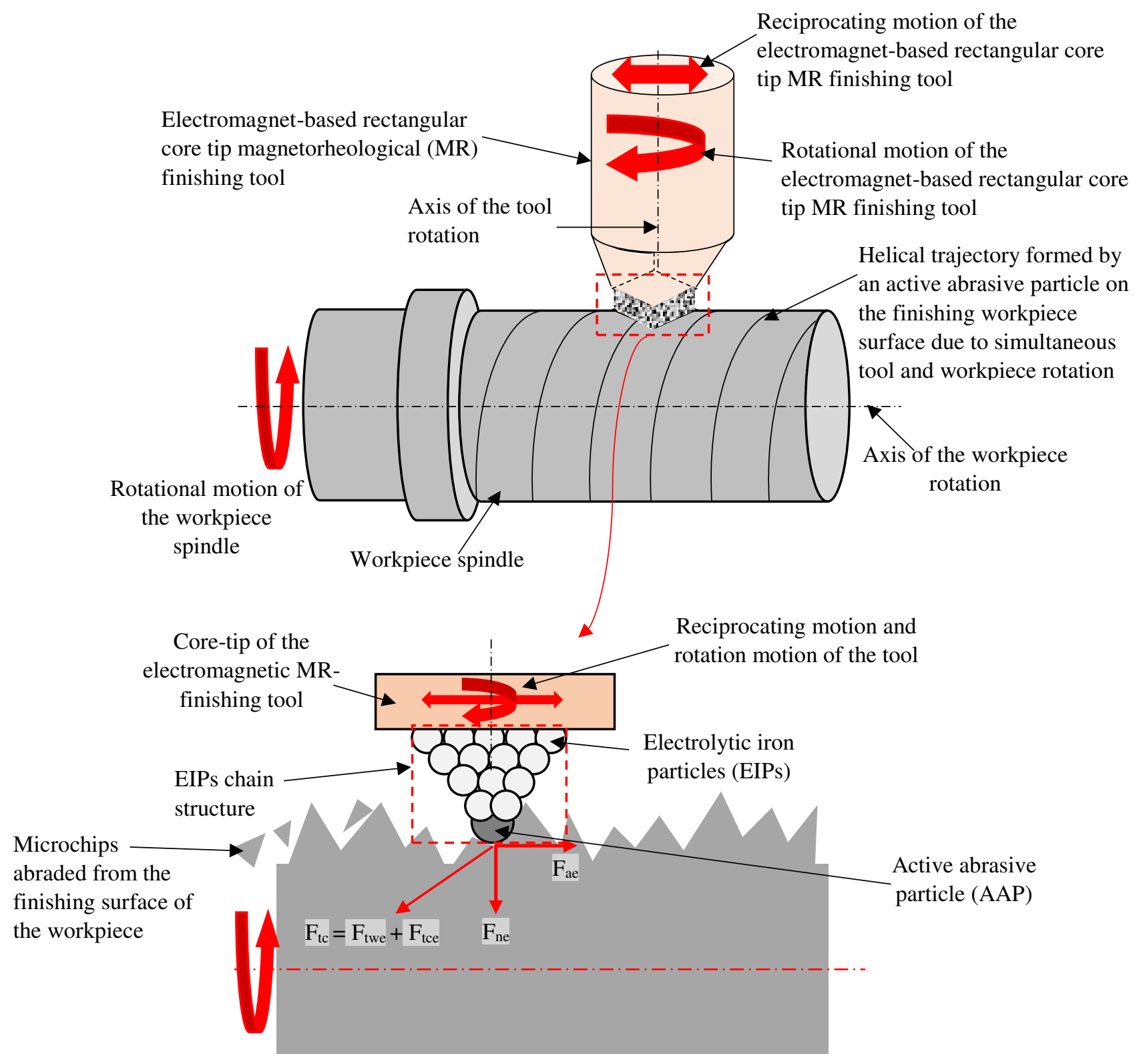

Fig. 4. MR finishing mechanism of the outer surface of the spindle workpiece. 


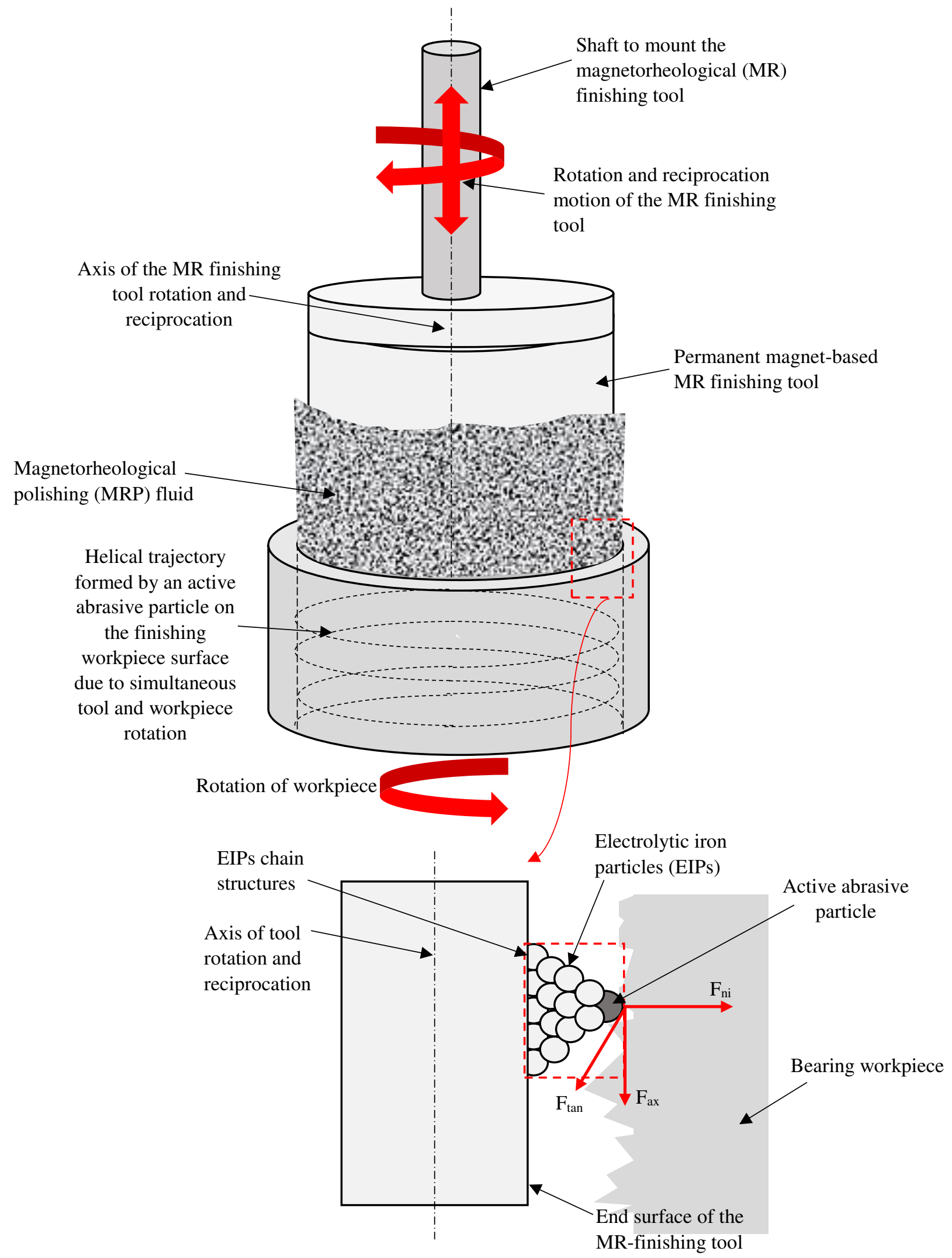

Fig. 5. MR finishing mechanism of the inner surface of the bearing. 
(a)

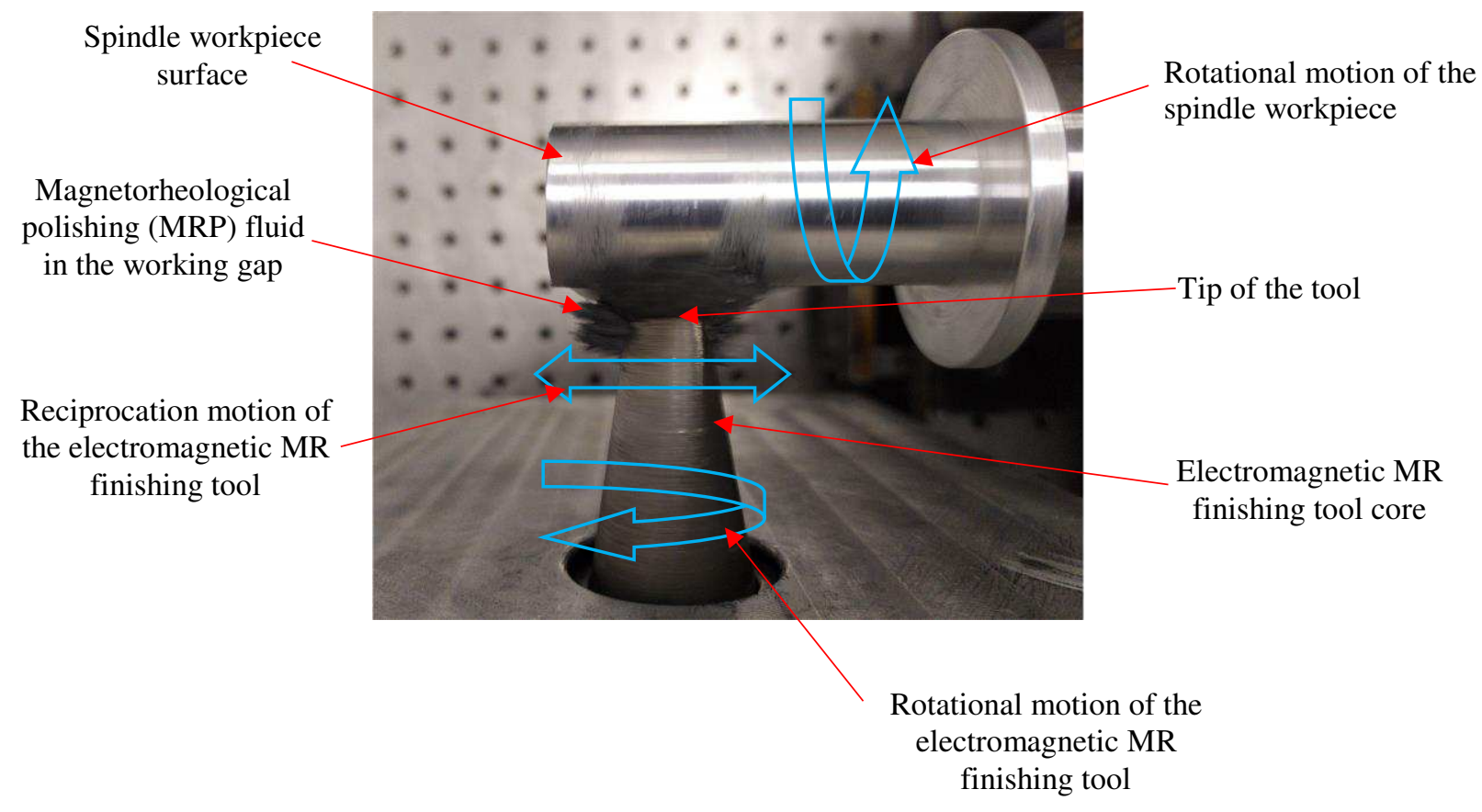

(b)

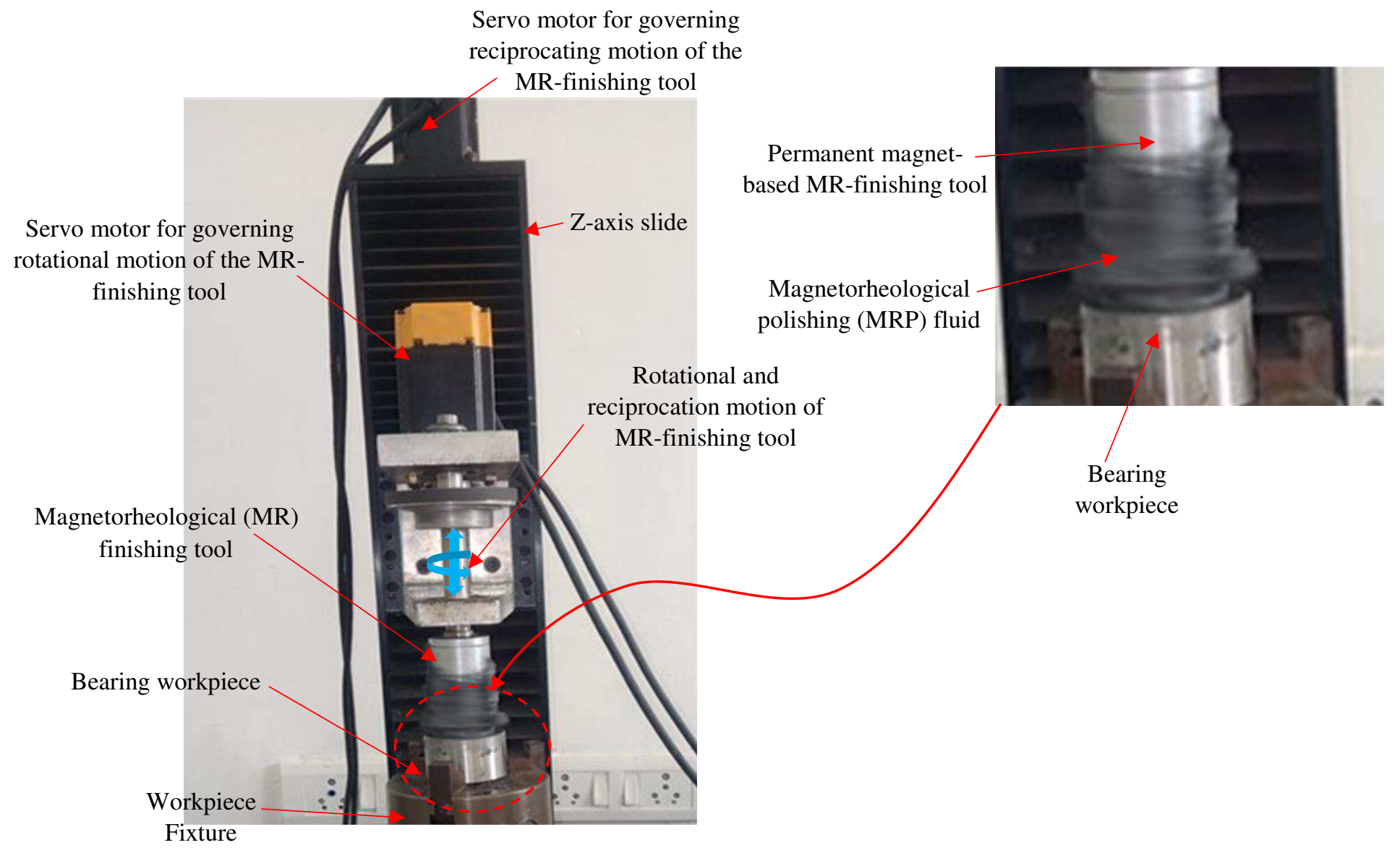

Fig. 6. Experimental setup of MR finishing for (a) spindle surface, and (b) bearing surface. 
(a)

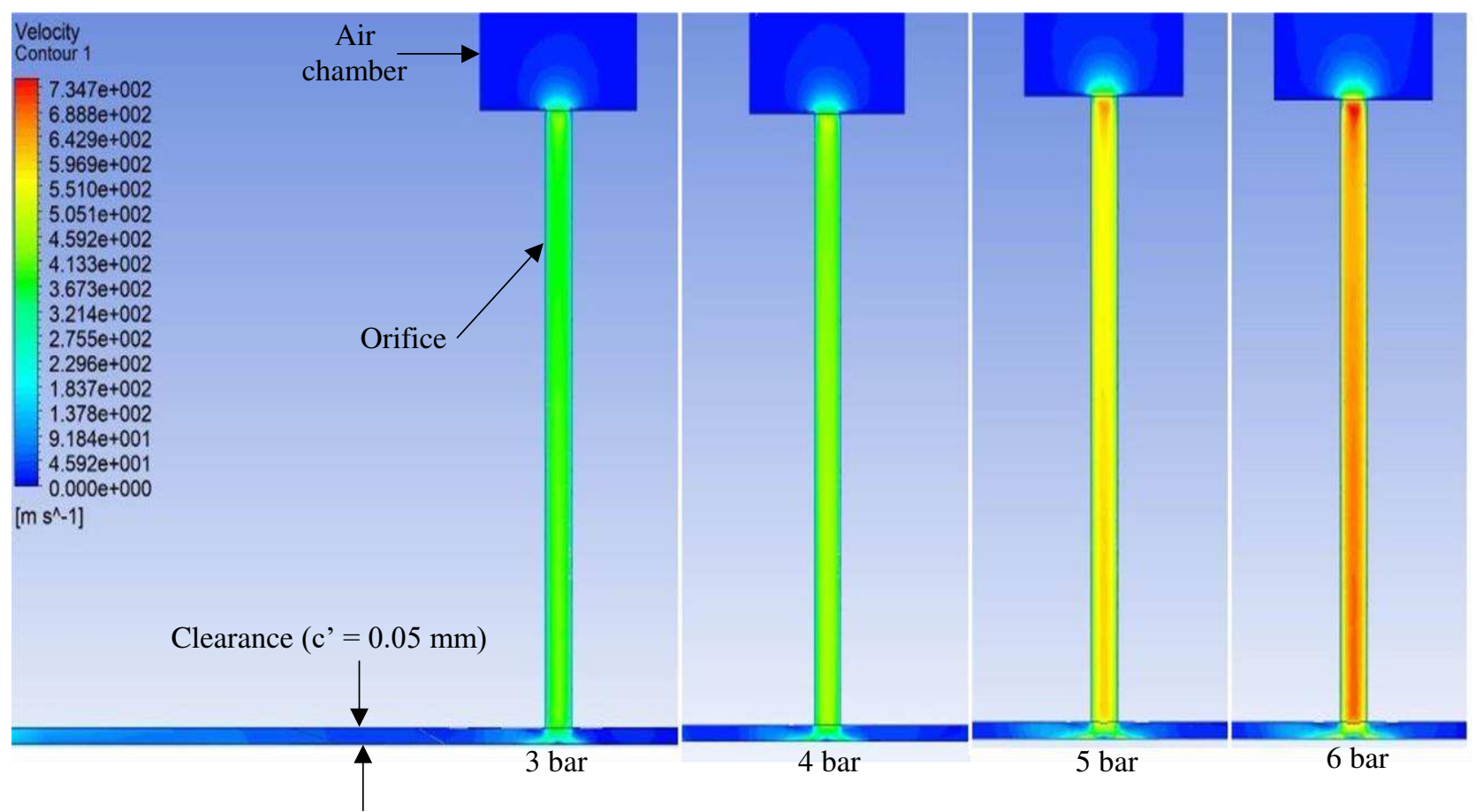

(b)

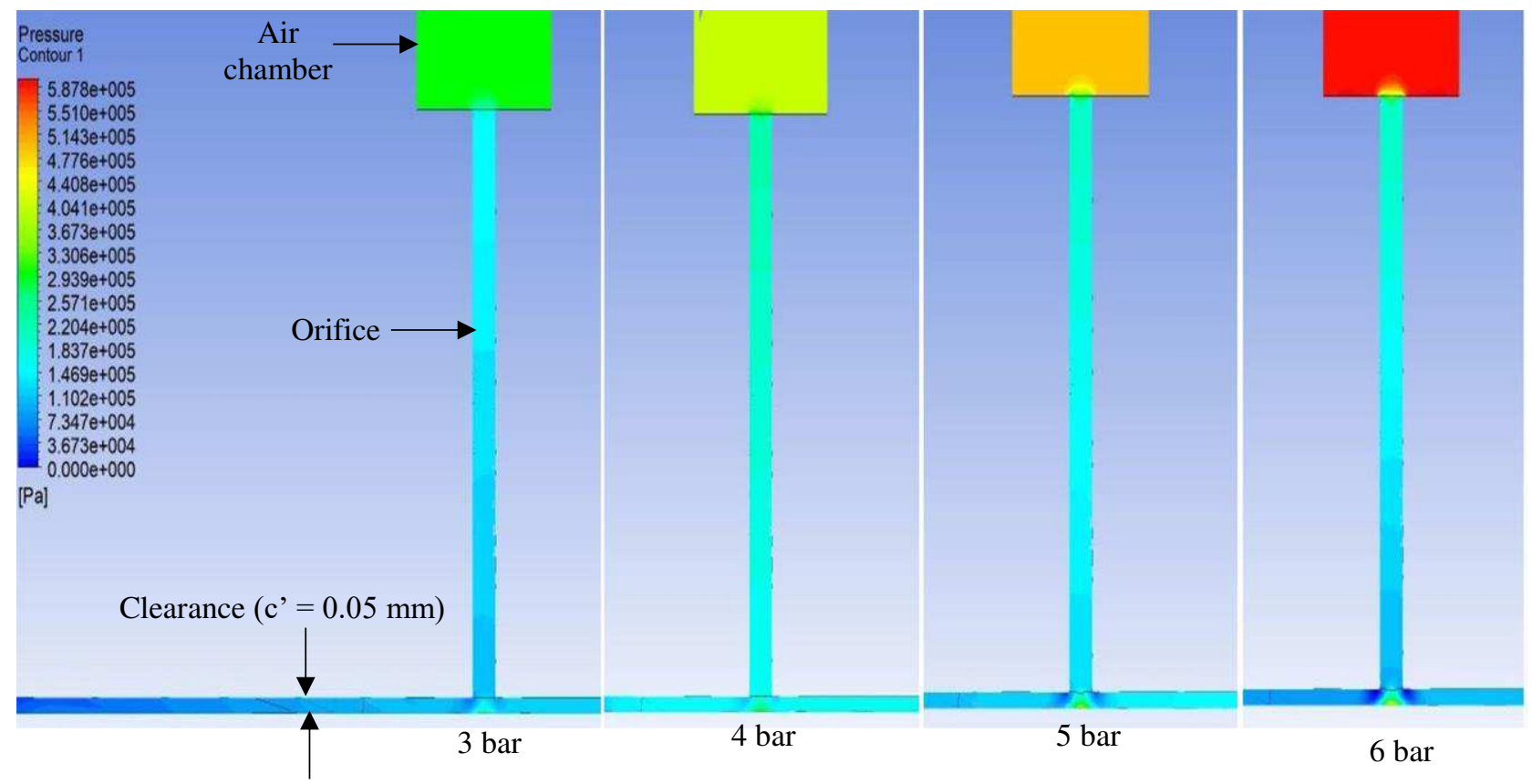

Fig. 7. (a) Velocity profiles, and (b) pressure profiles for the journal bearing. 
(a)

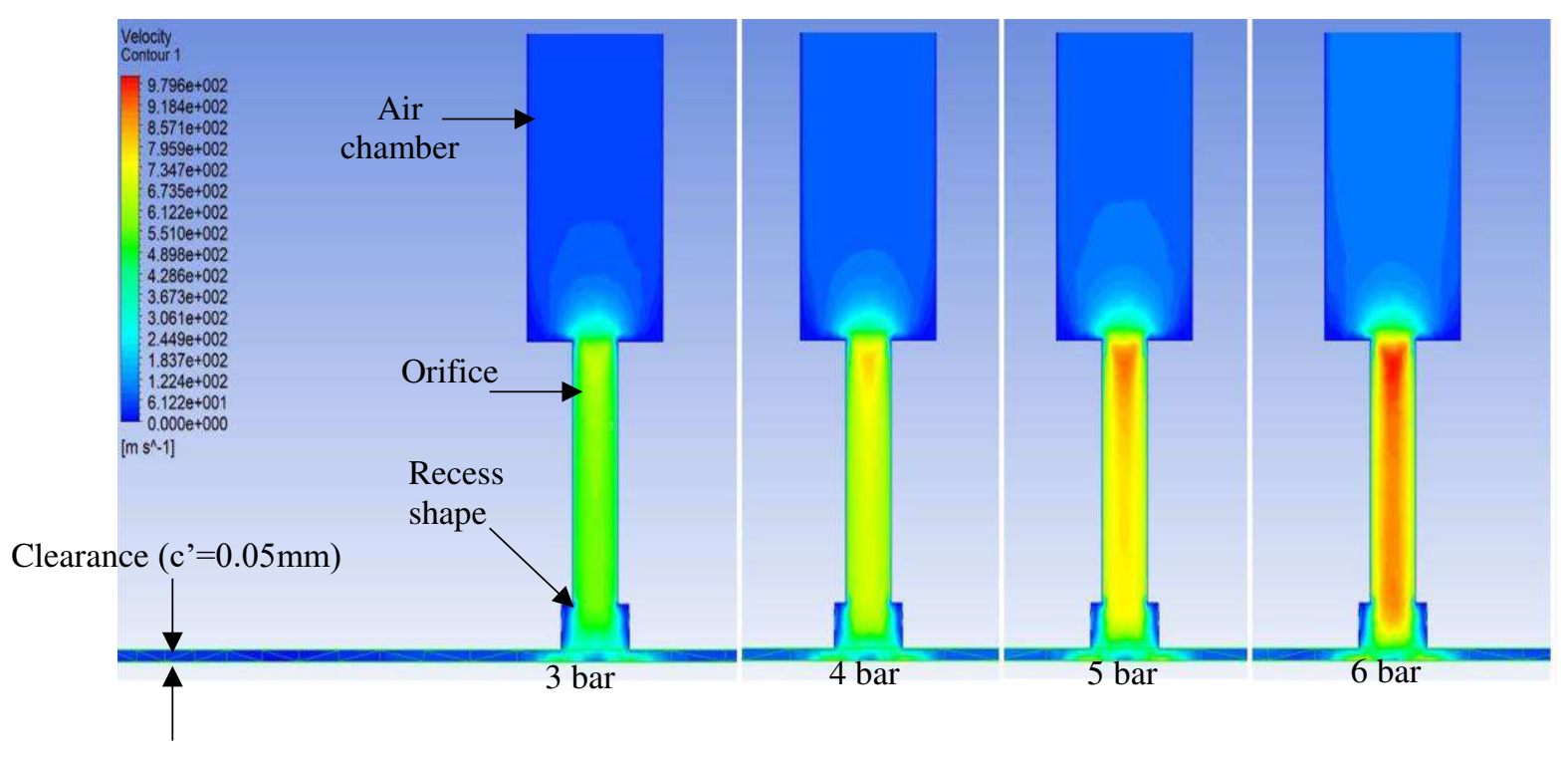

(b)

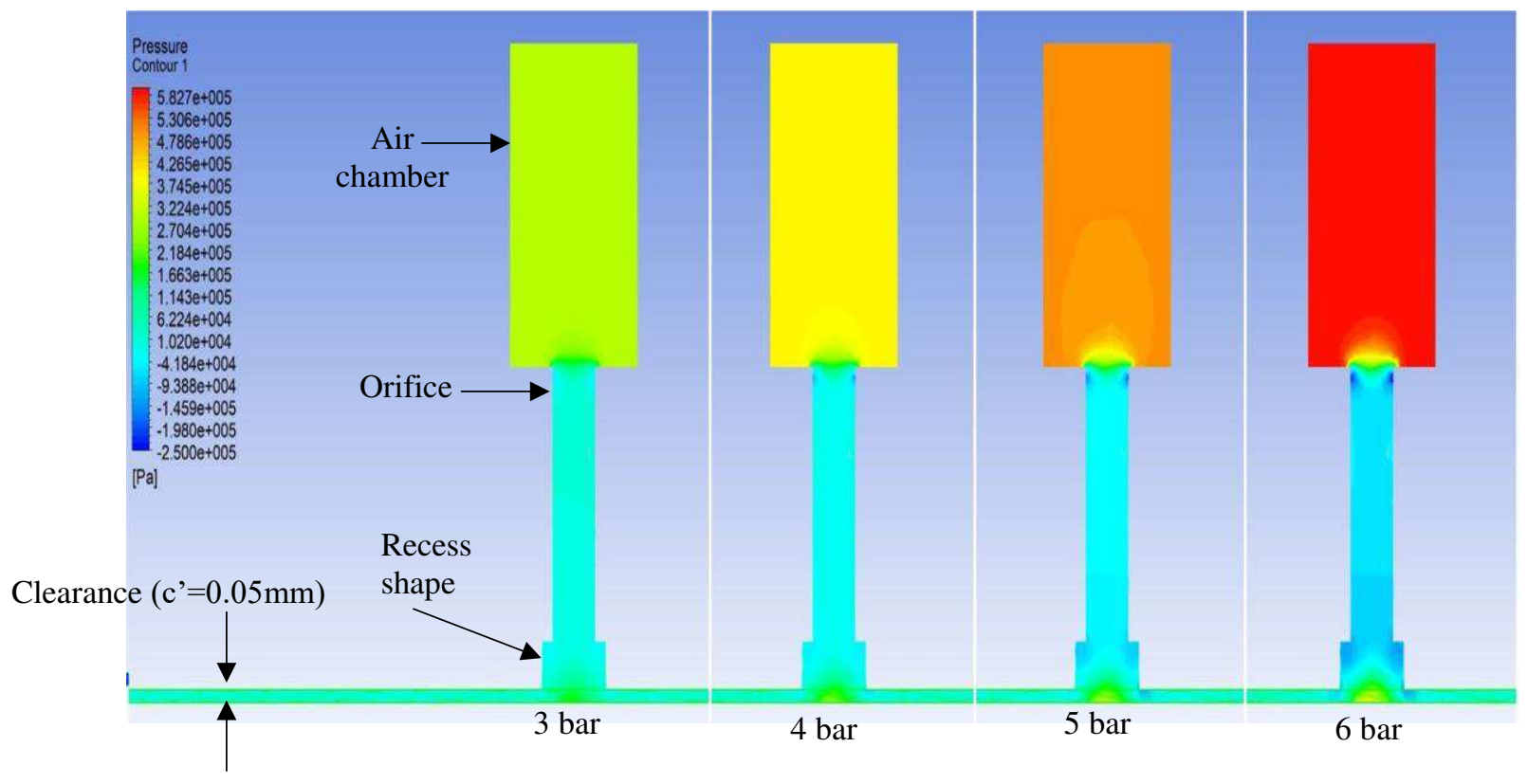

Fig. 8. (a) Velocity profiles, and (b) pressure profiles for the thrust bearing. 
(a)

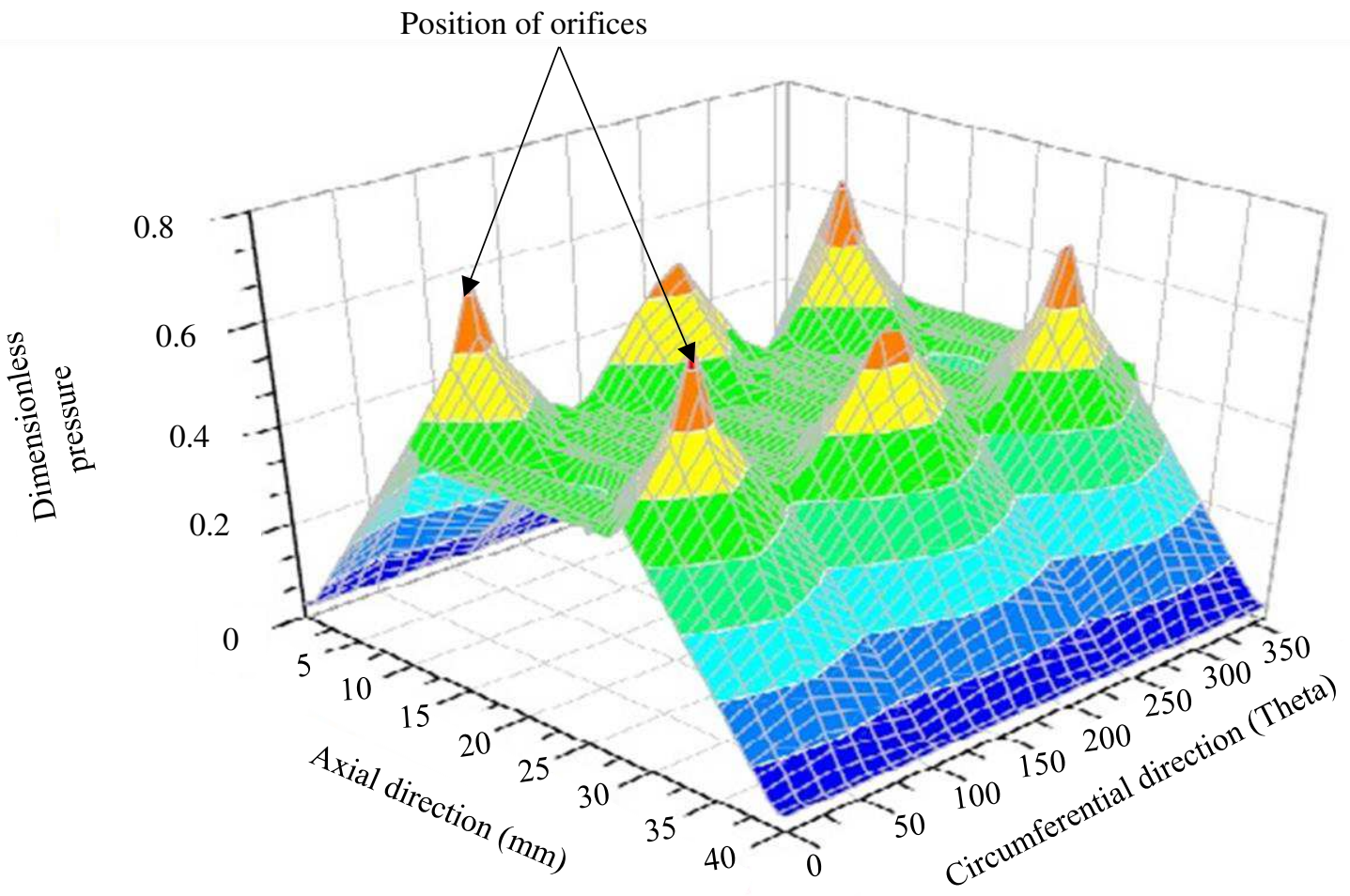

(b)

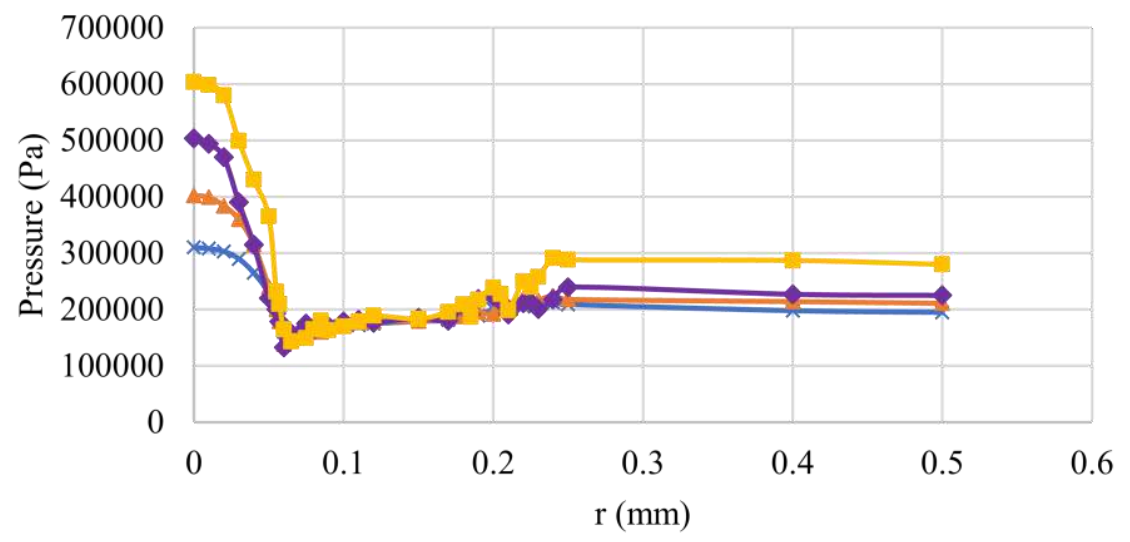

$\nVdash$ Pressure distribution at 3 bar $\longrightarrow$ Pressure distribution at 4 bar

$\leadsto$ Pressure distribution at 5 bar - - Pressure distribution at 6 bar

Fig. 9. The simulated pressure distribution of air film pressure in (a) journal bearing and (b) the curves in thrust bearing at supply pressure of $3 \mathrm{bar}, 4 \mathrm{bar}, 5 \mathrm{bar}$, and 6 bar. 
(a)

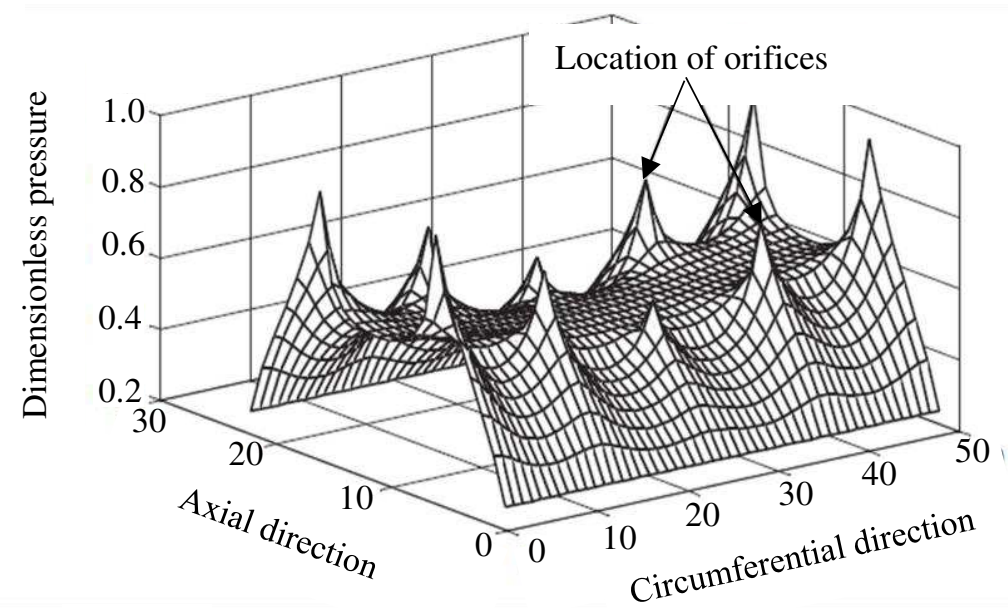

(b)

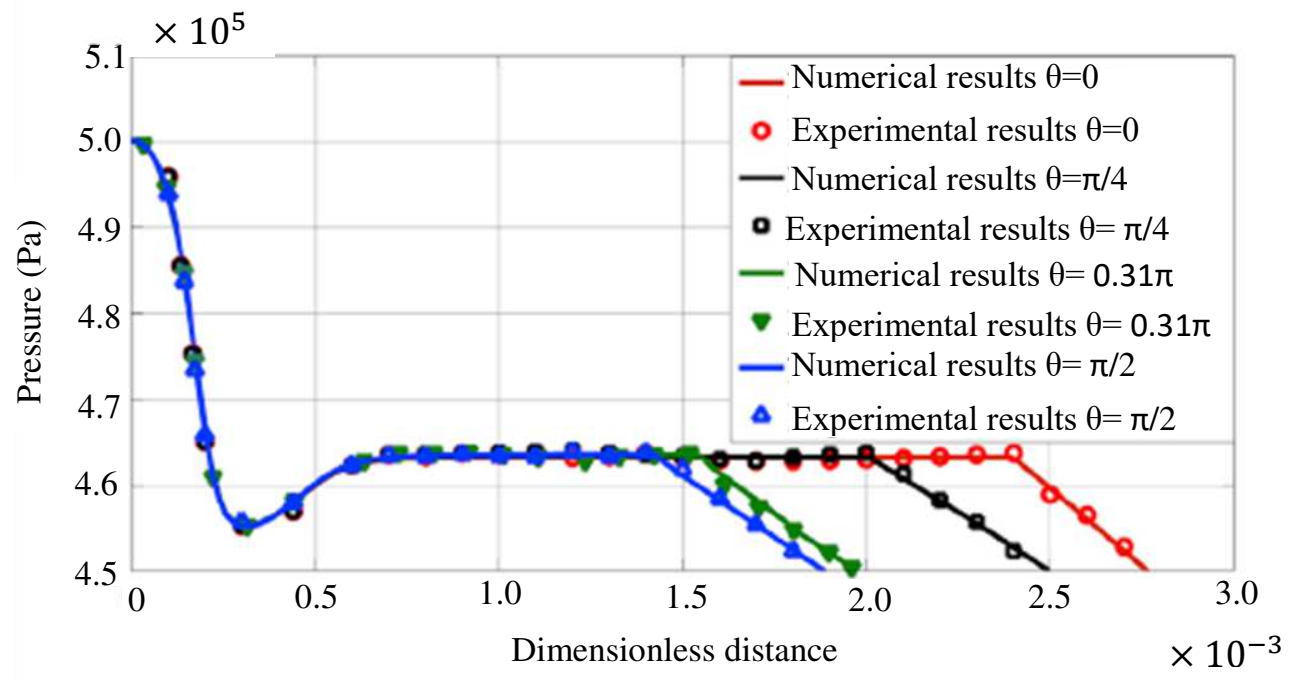

Fig. 10. Pressure distribution profile of air film for (a) journal bearing [23], and (b) thrust bearing [24]. 
(a)
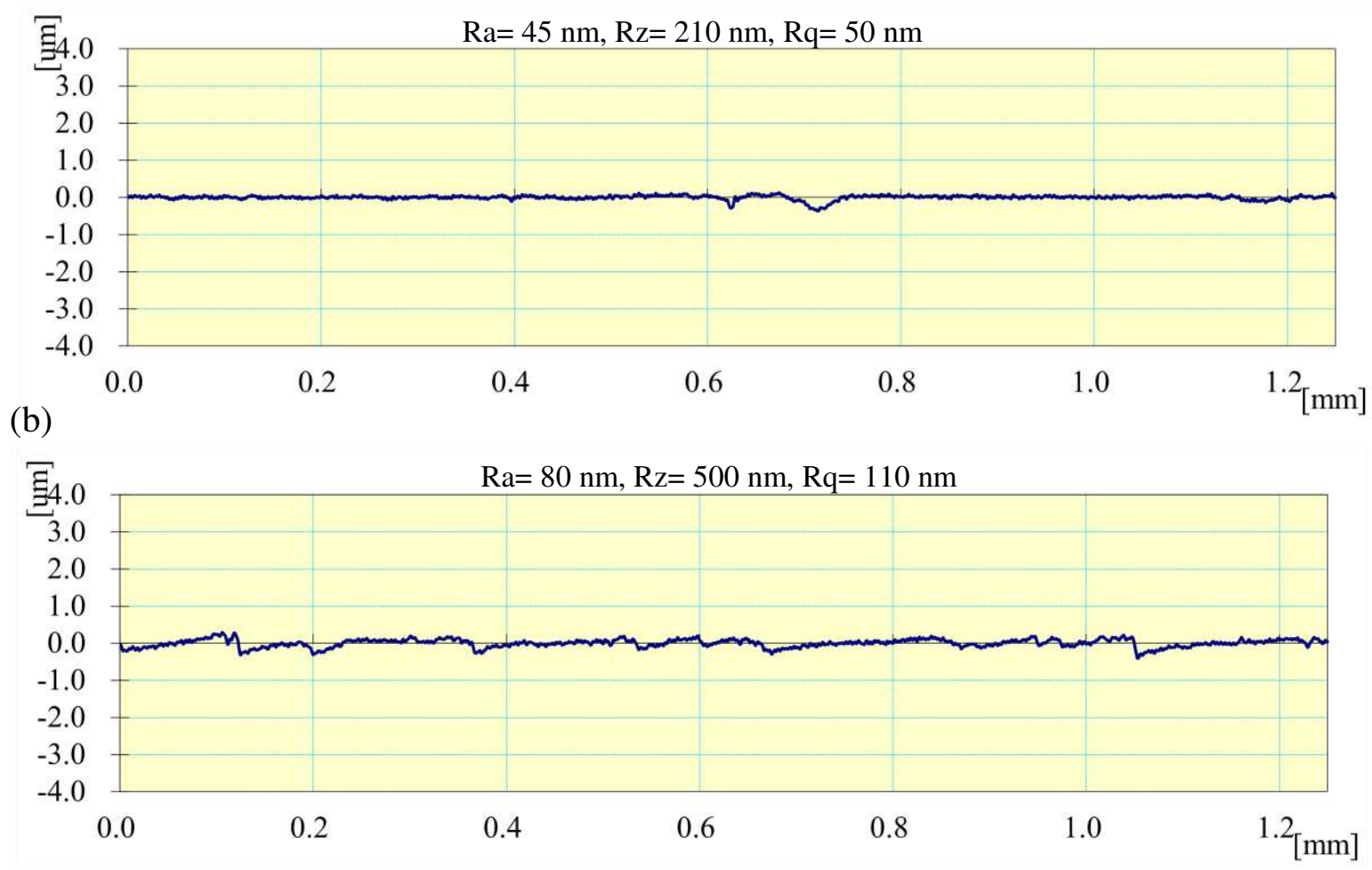

(c) Internal surface of

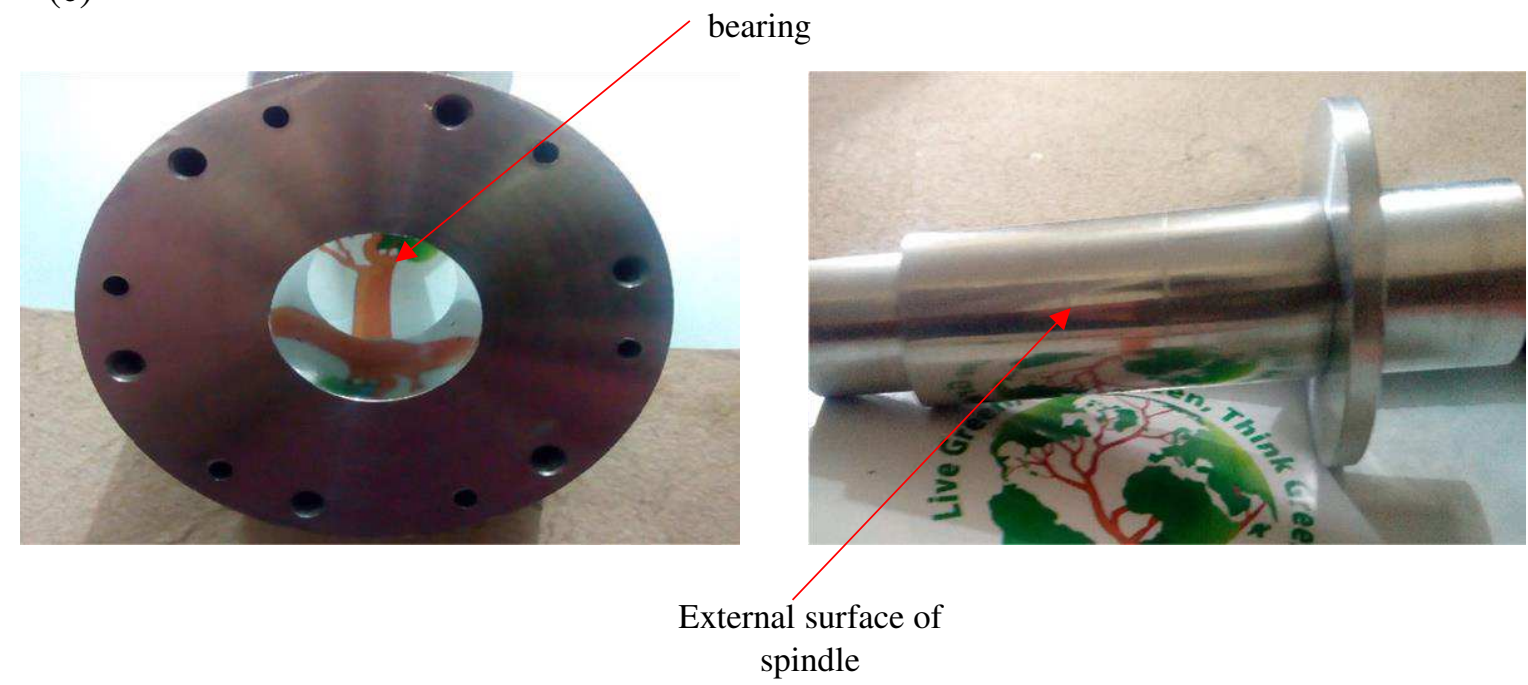

Fig. 11. Roughness profiles of (a) magnetorheological finished bearing surface, (b) magnetorheological finished spindle surface, and (c) mirror images of bearing components after MR finishing after 90 min. 
(a)

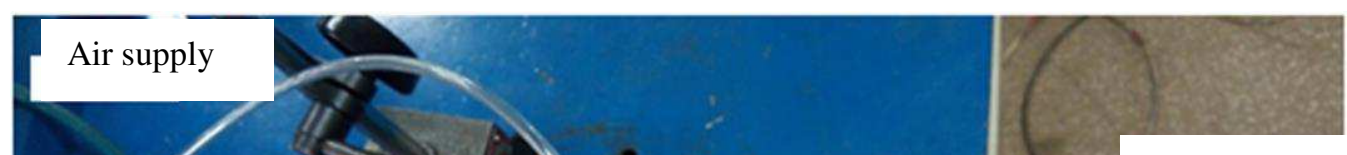

Displacement gauge

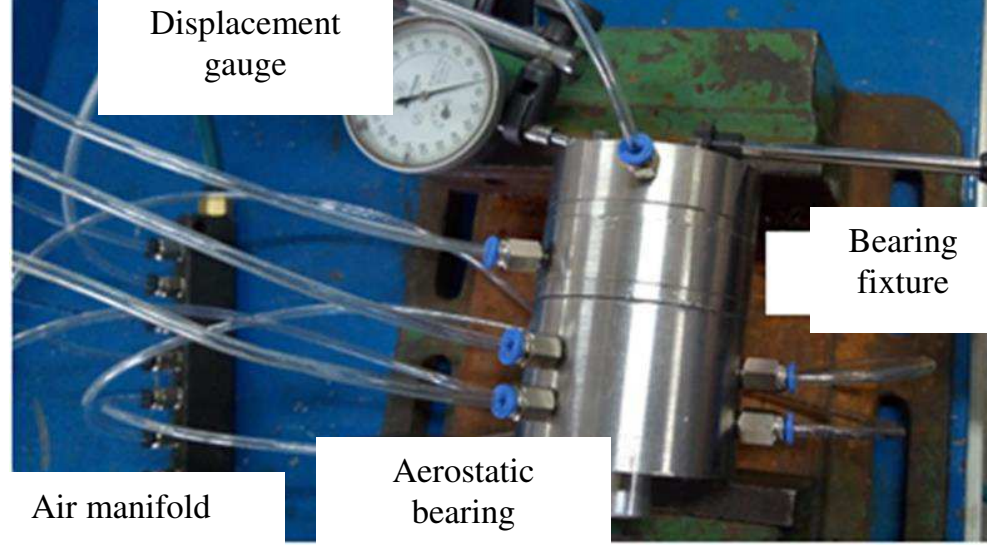

Push or pull dynamometer

(b)

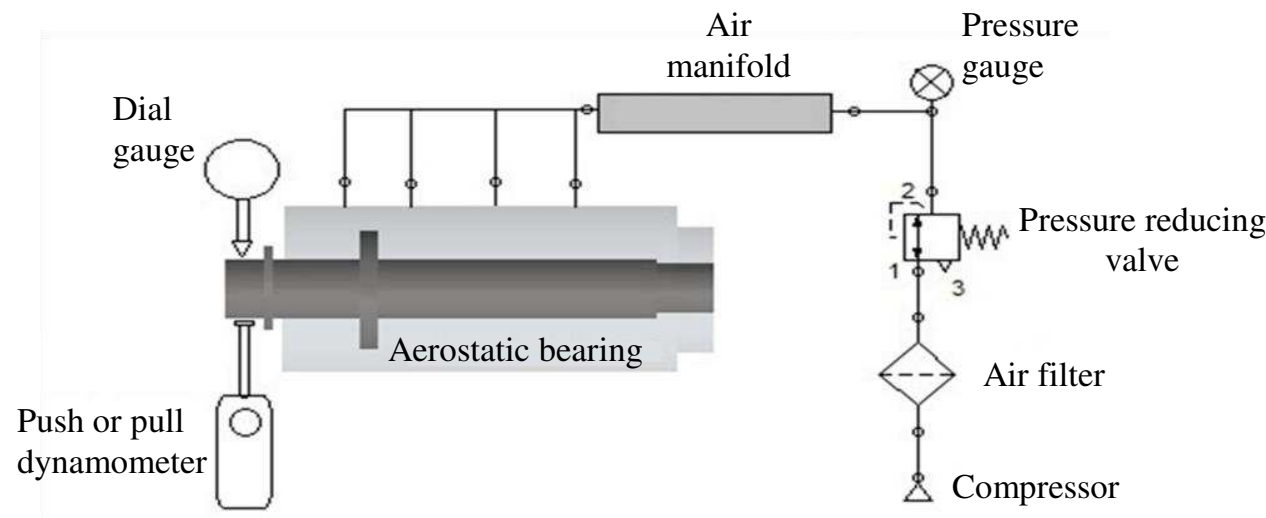

(c)

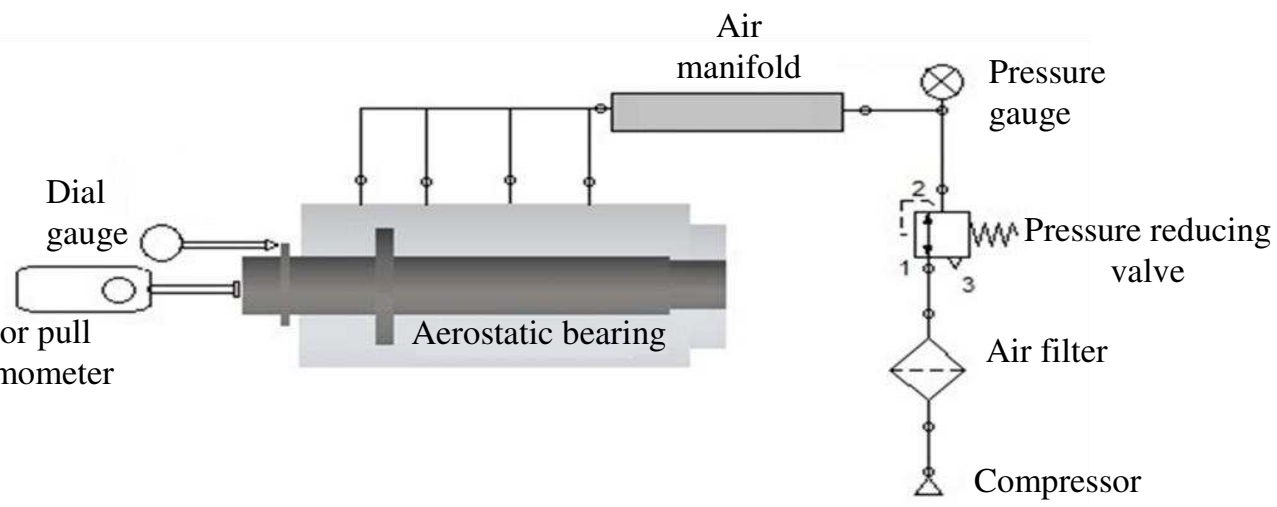

Fig. 12. (a) Experimental setup for aerostatic bearing, measurement instruments and air supply circuit for (b) journal bearing, and (c) thrust bearing. 
(a)

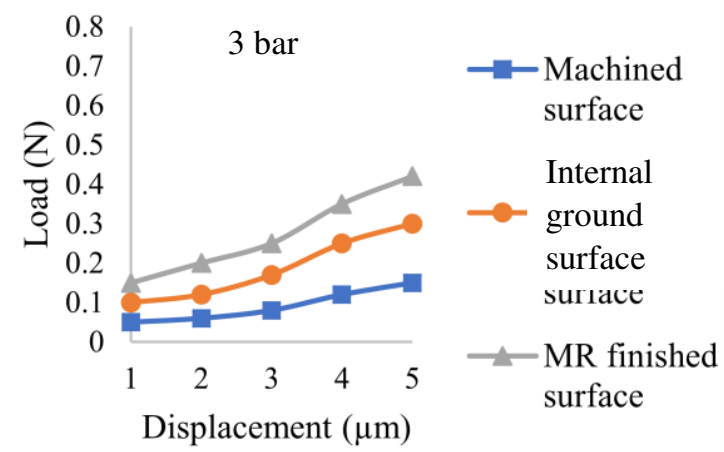

(c)

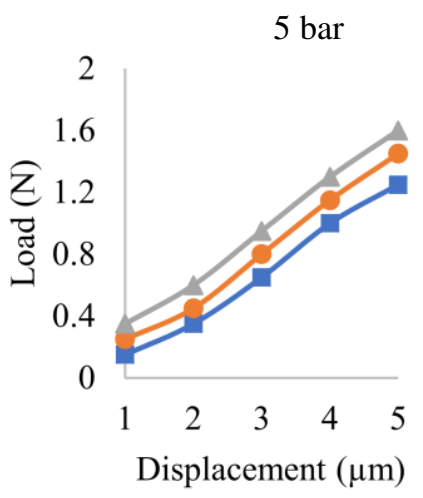

(b)

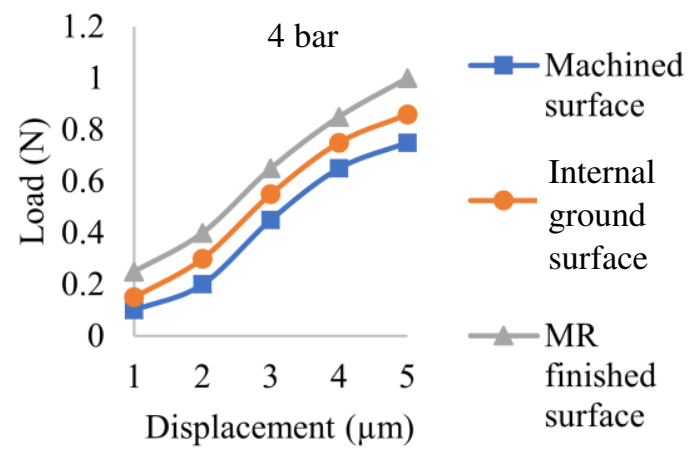

(d)

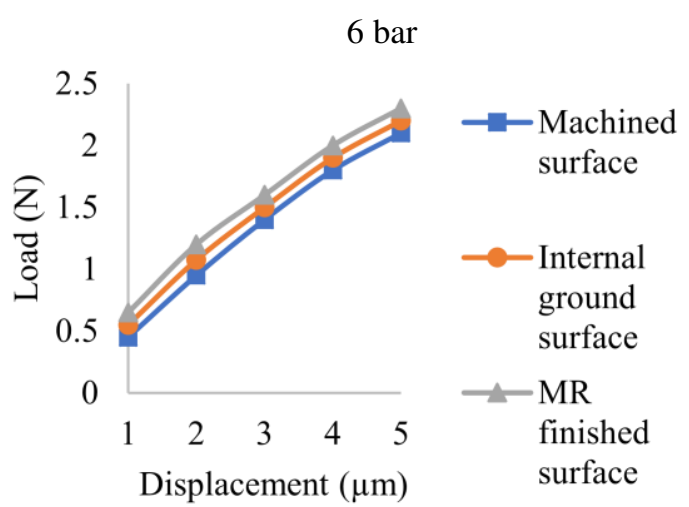

Fig. 13. Load-displacement analysis of journal bearing at different type of finished surfaces with supply pressure of (a) 3 bar, (b) 4 bar, (c) 5 bar, and (d) 6 bar. 


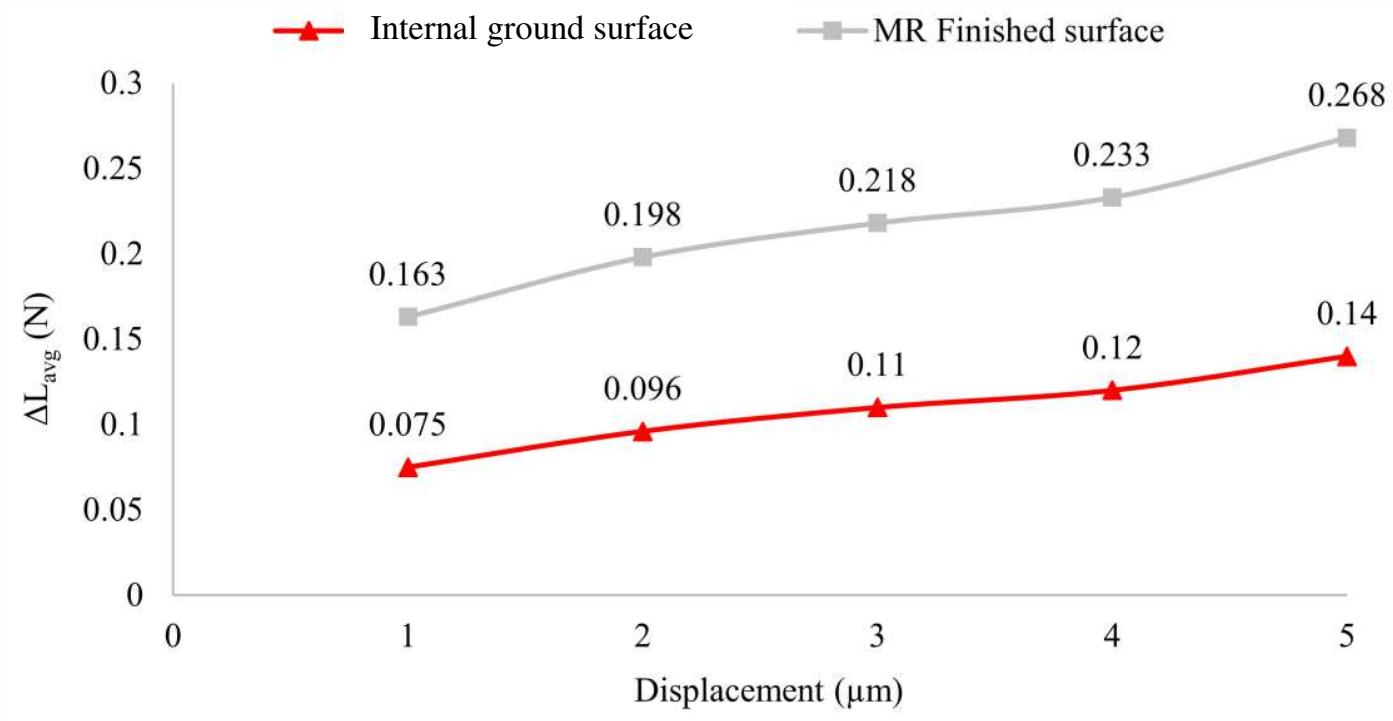

Fig. 14. Average change in load carrying capacity of journal bearing model at internal ground and MR finished surfaces. 
(a)

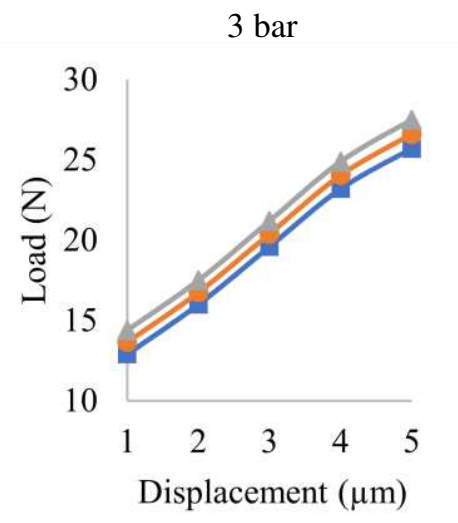

(c)

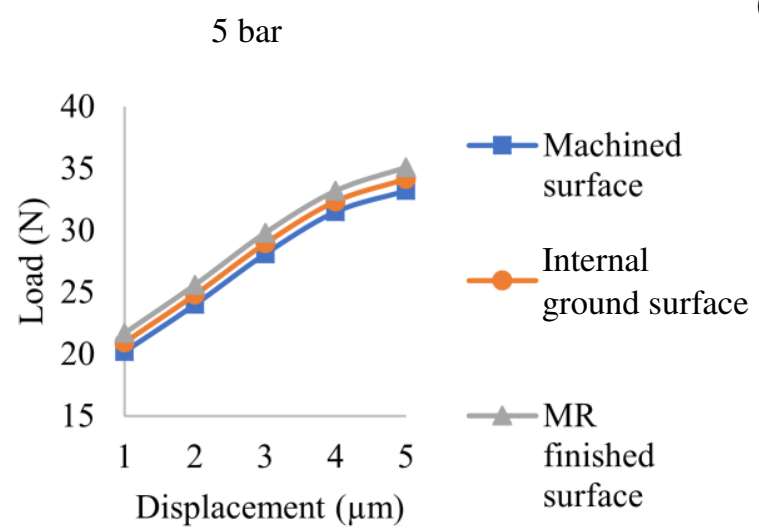

(b)

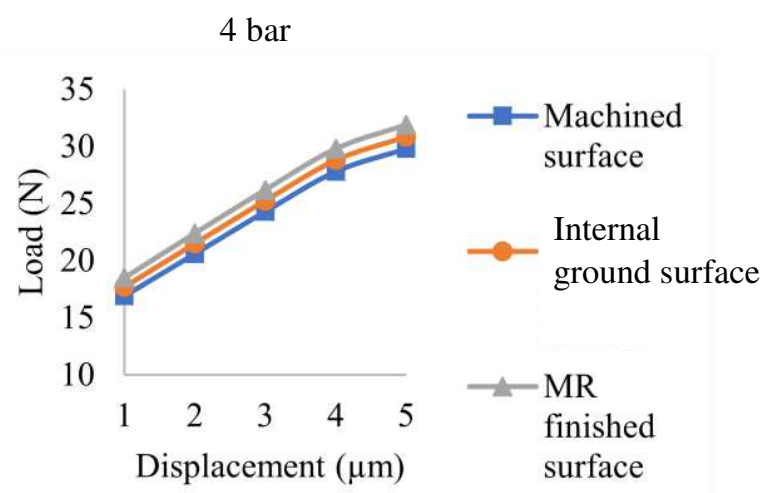

(d)

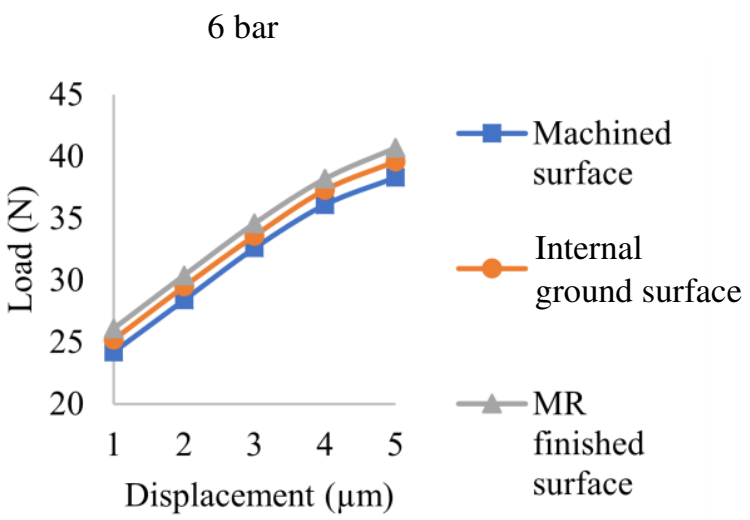

Fig. 15. Load-displacement analysis of thrust bearing at different type of finished surfaces with supply pressure of (a) 3bar, (b) 4bar, (c) 5bar, and (d) 6 bar. 


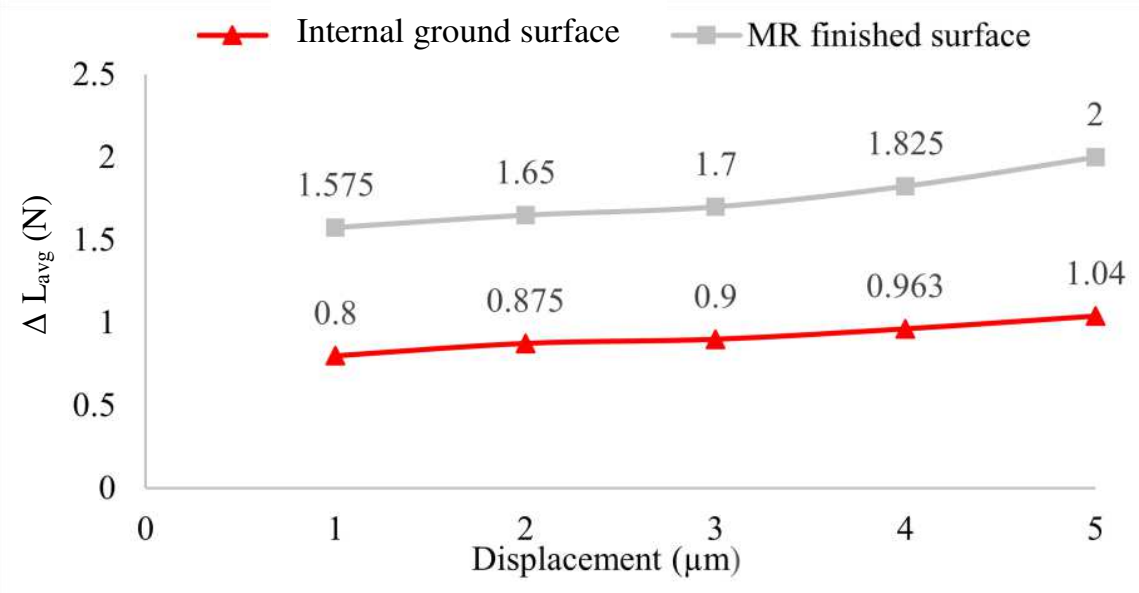

Fig. 16. Average change in load carrying capacity of thrust bearing model at internal grinding and MR finished surfaces. 